Article

\title{
A new method for quantifying heterochrony in evolutionary lineages
}

\author{
James C. Lamsdell (10)
}

\begin{abstract}
The occupation of new environments by evolutionary lineages is frequently associated with morphological changes. This covariation of ecotype and phenotype is expected due to the process of natural selection, whereby environmental pressures lead to the proliferation of morphological variants that are a better fit for the prevailing abiotic conditions. One primary mechanism by which phenotypic variants are known to arise is through changes in the timing or duration of organismal development resulting in alterations to adult morphology, a process known as heterochrony. While numerous studies have demonstrated heterochronic trends in association with environmental gradients, few have done so within a phylogenetic context. Understanding species interrelationships is necessary to determine whether morphological change is due to heterochronic processes; however, research is hampered by the lack of a quantitative metric with which to assess the degree of heterochronic traits expressed within and among species. Here I present a new metric for quantifying heterochronic change, expressed as a heterochronic weighting, and apply it to xiphosuran chelicerates within a phylogenetic context to reveal concerted independent heterochronic trends. These trends correlate with shifts in environmental occupation from marine to nonmarine habitats, resulting in a macroevolutionary ratchet. Critically, the distribution of heterochronic weightings among species shows evidence of being influenced by both historical, phylogenetic processes and external ecological pressures. Heterochronic weighting proves to be an effective method to quantify heterochronic trends within a phylogenetic framework and is readily applicable to any group of organisms that have well-defined morphological characteristics, ontogenetic information, and resolved internal relationships.
\end{abstract}

James C. Lamsdell. Department of Geology and Geography, West Virginia University, Morgantown, West Virginia 26506, U.S.A. E-mail: james.lamsdell@mail.wvu.edu

Accepted: 15 March 2020

Data available from the Dryad Digital Repository: https://doi.org/10.5061/dryad.pzgmsbcgp

\section{Introduction}

Understanding the evolutionary patterns and processes that drive the generation of new phenotypes and occupation of previously unexploited environments (the occurrence of novelty and innovation, sensu Erwin 2017) is a fundamental goal of evolutionary study. The topic of novelty and innovation has most frequently been explored through the lens of adaptive radiation (Losos 2010; Yoder et al. 2010), which posits that ecological opportunities combined with chance phenotypic evolution permits exploration of new ecospace (Stroud and Losos 2016). This model of adaptive radiation has been invoked as the dominant causal factor of major evolutionary events in Earth's history, including the Cambrian explosion (Erwin and Valentine 2013), invasion of freshwater ecosystems (Davis et al. 2018), colonization of land (Benton 2010), and recovery from mass extinction events (Toljagić and Butler 2013). In turn, the innovation of phenotypes is recognized to occur through heritable alterations in the timing of an organism's development, a process known as heterochrony (McNamara and McKinney 2005; McNamara 2012; Colangelo et al. 2019). Therefore, heterochronic processes result in new morphological characteristics that can allow organisms to exploit new environments and subsequently diversify.

Natural biological systems are complex entities, in which both environmental interaction and historical components are potentially equally important (Eldredge and Salthe 1984; Vrba and Eldredge 1984; Erwin 2015b;

(C) 2020 The Paleontological Society. This is an Open Access article, distributed under the terms of the Creative Commons Attribution licence (http://creativecommons.org/licenses/by/4.0/), which permits unrestricted re-use, distribution, and reproduction in any medium, provided the original work is properly cited. 
Lamsdell et al. 2017; Congreve et al. 2018). Evolutionary trajectories are defined by the interaction of two semi-independent genealogical and ecological hierarchies (Eldredge and Salthe 1984; Congreve et al. 2018); as such, ecological changes have the potential to influence heterochronic processes to the same extent as heterochronic changes might alter the potential for ecological occupation. Therefore, pluralistic approaches are required to determine the relative importance of ecological or evolutionary mechanisms behind biotic responses (Lamsdell et al. 2017; Tucker et al. 2017; Congreve et al. 2018), representing a synthesis of macroevolutionary and macroecological topics and methods.

Heterochrony, however, has rarely been studied within an explicitly phylogenetic context (Bardin et al. 2017). Cranial evolution of anguimorphan lizards (Bhullar 2012) and theropod dinosaurs (Bhullar et al. 2012) has been examined by placing heterochronic changes within a phylogenetic hypothesis, but no attempt to incorporate ecological occupation into such investigations has been made. These studies have also focused on only a subset of morphological characters that may show heterochronic trends, which may obscure overall patterns of heterochrony within lineages, as traits display patterns of mosaic evolution (Hopkins and Lidgard 2012; Hunt et al. 2015), whereby individual traits may exhibit different modes of evolution within a lineage. Recognizing overall heterochronic trends within a lineage beyond the trajectories of individual traits is key to understanding the role of heterochrony in evolution. Furthermore, appropriate methods to quantitatively compare heterochronic trends between lineages have been lacking until now. Here, I use phylogenetic paleoecology to analyze patterns in ecological affinity and heterochronic trends across xiphosuran chelicerates and present a new metric for quantitatively representing heterochronic changes within an evolutionary lineage.

\section{Data and Methods}

Quantifying Heterochrony.-A novel approach for quantifying heterochrony is proposed herein, whereby a character matrix comprising a series of multistate characters coded for each species within the analysis is developed. Each character represents an aspect of morphology that may exhibit a paedomorphic, peramorphic, or neutral heterochronic expression. The peramorphic and paedomorphic conditions for each character are determined based on a ranked series of criteria:

1. direct observations of ontogenetic changes within the target species;

2. ontogenetic changes observed in closely related species;

3. ontogenetic changes observed in extant relatives;

4. comparison with outgroup juvenile morphology or ontogeny for character polarity; and

5. comparison with outgroup adult morphology for character polarity.

Once the polarity of the morphology of heterochronic expression for each character is established, characters are coded for each species and assigned a score. A paedomorphic condition is assigned a negative $(-1)$ score, a peramorphic condition is assigned a positive $(+1)$ score, and a neutral condition is assigned a score of 0 . If a character cannot be coded for a given species, either due to it not being preserved or its condition being otherwise unclear, it is not given a score and does not contribute to the analysis. The total number of characters within the matrix depends on the number of identifiable heterochronically influenced traits within a lineage; as such, organisms with more complex morphologies and betterunderstood ontogenies will result in larger heterochronic matrices. A larger matrix allows for increased granularity in the heterochronic weighting, and ideally a matrix will comprise 10 or more characters; however, it is possible to generate a heterochronic weighting for a taxon that has as few as three characters coded.

Each of the characters coded for a species in the matrix contributes to the heterochronic weighting of the species, calculated as:

$$
H w_{j}=\frac{\sum_{i=1}^{n} \eta_{i}}{n}
$$

where $H w$ is the heterochronic weighting of species $j$, derived from the mean of the 
combined heterochronic scores $(\eta)$ of $n$ characters, resulting in a value between 1.00 (more peramorphic) and -1.00 (more paedomorphic). In turn, the heterochronic weighting of a given clade is calculated as:

$$
[H w]_{k}=\frac{\sum_{j=1}^{N} H w w_{j}}{N}
$$

where $[\mathrm{Hw}]$ is the heterochronic weighting of clade $k$, derived from the mean of the combined heterochronic weightings ( $H w)$ in $N$ species, again resulting in a value between 1.00 and -1.00 . The heterochronic weighting of a clade therefore represents the average of the heterochronic weightings of its constituent species; it is explicitly not an ancestral state reconstruction. What heterochronic weighting does ensure is that all taxa within an analysis have a directly comparable metric, permitting analysis of heterochronic trends and correlation with other evolutionary phenomena. While the scale of the heterochrony metric raw values within an analysis is relative and cannot be directly compared between analyses, patterns and timing of heterochronic shifts can be directly compared between datasets in an identical manner to quantitative analyses of morphospace (Korn et al. 2013; Hopkins and Gerber 2017).

To determine whether the heterochronic weighting of a clade represents a concerted trend shift distinct from what could be expected from random, nondirectional evolution, the observed clade scores are randomized across the tree topology. In total, 100,000 randomizations are performed, with the distribution of the randomized heterochronic weightings then collated into a histogram for each clade to which the observed clade heterochronic weighting can be directly compared. If the actual weighting score falls within either tail of the distribution, the weighting is significantly different from what would be expected under random (nondirectional) character change. Randomizing the heterochronic weightings across the observed phylogeny accounts for vagaries such as clade size and topological relationships that may impact the distribution of heterochronic weighting scores. The heterochronic weights retrieved for a given clade are therefore compared with a distribution of weight scores over an identical topology; as such, randomized distributions should be generated for each topology used in an analysis. In this way, disparate analyses can determine whether clades fall within the tails of the expected heterochronic weighting distribution given their phylogenetic topology.

Node-versus Tip-based Analyses.-Scores for heterochronic weighting can be applied two ways, through either a node-based or a tipbased analysis (Fig. 1). Applying heterochronic weighting through node-based calculations accurately encompasses the fact that whether a condition for a given taxon is peramorphic, paedomorphic, or neutral is dependent on the condition in its ancestor as inferred by ancestral state reconstruction, and so it is possible for the polarity of a character to change over the evolutionary history of a clade. As such, when applying node-based calculations, it is critical to document the polarity of each character for each node in the phylogeny. Heterochronic weights are calculated for nodes and are reset at the base of each branch of the phylogeny, with individual character weights representing the inferred shift or transition from the ancestral condition. Node-based application of heterochronic weighting more accurately reflects the actual process of heterochrony; however, it is sensitive to sampling, as failing to sample a species can result in an incorrect assumption of character polarity for a given node, while large gaps in sampling can result in unnatural stacking of transitions at sampled nodes. The analysis also becomes incredibly sensitive to phylogenetic topology, as the relative order in which nodes occur will have a major impact on character polarity. Therefore, node-based heterochronic weighting ideally requires a wellconstrained and dated phylogeny for an evenly sampled group with good ontogenetic data. In practice, only a minority of clades may combine all of these attributes, limiting the extent to which heterochronic weighting can be applied from a node-based perspective - although the promise of phylogenetic advances in a variety of molluscan groups such as ammonoids and gastropods, which regularly preserve details of their ontogeny and have a good fossil record, 


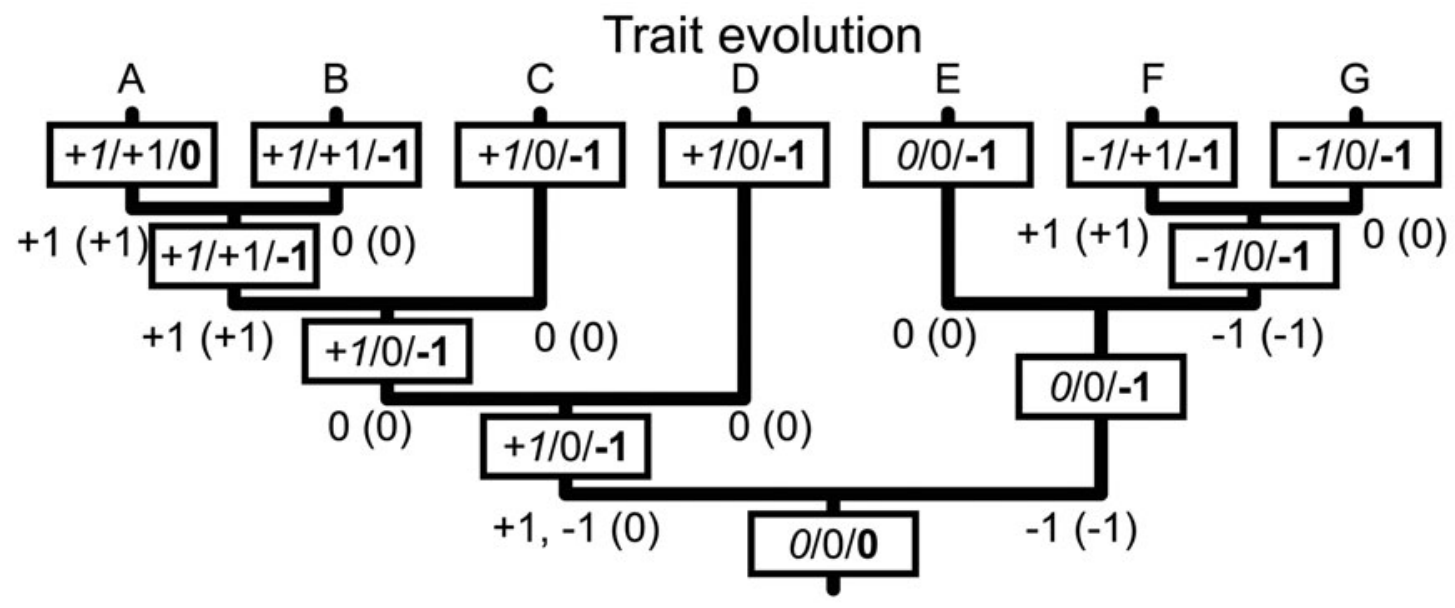

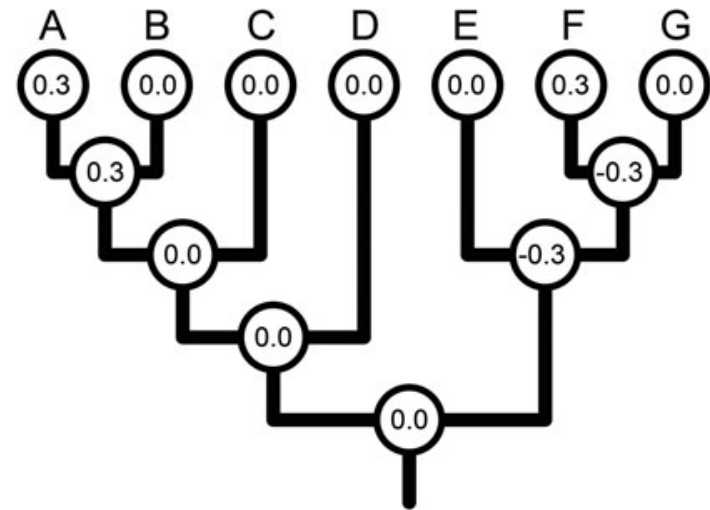

Node-based calculations

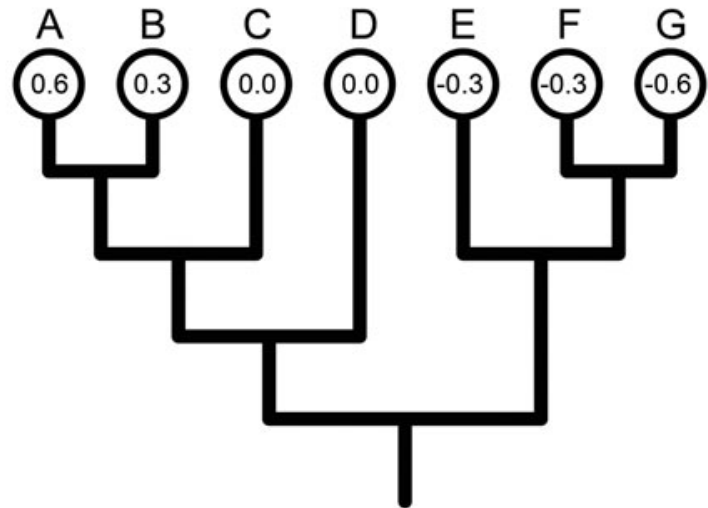

Tip-based calculations

FIGURE 1. Example of heterochronic weightings calculated from three traits evolving across a lineage comprising taxa A-G. In the top tree, evolution of the three traits is shown with their condition (peramorphic +1 , paedomorphic -1 , or neutral 0 ) for each species and internal node of the phylogeny shown in boxes. Transitions between character states are shown beneath each branch. The polarity of a transition is dependent on the condition of the character at the preceding node; therefore, a transition to 0 from -1 would be positive (a peramorphic transition), while a transition to 0 from +1 would be negative (a paedomorphic transition). Node-based calculations are shown on the bottom left, where heterochronic weights are derived from the transitions leading to each node or tip species, while tip-based calculations of heterochronic weights derived from the terminal character conditions of tip species are shown on the bottom right. Both analytical variations accurately capture the overall peramorphic trend among species A and B and the paedomorphic trend from species $\mathrm{E}$ to G. Notably, the tip-based application of the method fails to recognize the peramorphic reversal in species F; however, tipbased heterochronic weights would recognize the peramorphic influence if this were to develop into a long-term trend. Node- and tip-based calculations of heterochronic weights are therefore both equally accurate with regard to recognizing overall trends, but node-based calculations are more precise.

marks them as potential candidates for nodebased heterochronic weighting.

Alternatively, the tip-based application of heterochronic weighting provides a grand average of heterochronic traits within observed taxa compared with the root character polarity. Rather than tracing the transition of the heterochronic event, tip-based heterochronic weighting quantifies the overall outcome of heterochronic events. This makes the method less precise than its node-based articulation, as it may fail to recognize relative polarity changes in characteristics, but is more broadly applicable to groups with uneven sampling or uncertain phylogenetic topology. Tip-based heterochronic weighting gives an overall 
indication of peramorphic or paedomorphic trends over the evolutionary history of a clade; in this way, it is similar to the method recently used by Martynov et al. (2020) to study paedomorphosis in nudibranchs, with the distinction that heterochronic weighting provides a quantitative rather than qualitative assessment of the degree of peramorphic or paedomorphic traits within a species. For the present study, heterochronic weighting was applied using the tip-based procedure, as sampling of Xiphosura is uneven across their evolutionary history, as demonstrated by the lack of Silurian exemplars. This is considered an appropriate field test of the method, as I suspect that tip-based analyses will form the bulk of any subsequent studies that adopt heterochronic weighting.

Heterochronic Character Matrix.-A heterochronic character matrix for Xiphosura was assembled comprising 20 characters. Characters and their peramorphic and paedomorphic conditions were developed following the criteria detailed in "Quantifying Heterochrony". The characters encompass a wide variety of xiphosuran morphology, equally divided between traits of the prosoma (anterior tagma) and traits of the thoracetron (posterior tagma) (Figs. 2, 3, Table 1). The resulting matrix, coded for 54 xiphosurid taxa, is available in the Supplementary Material. While a number of aspects of these characters also appear in the phylogenetic character matrix, several (such as body size) are not considered appropriate phylogenetic characters and are not incorporated into the phylogenetic analysis. Those heterochronic characters that are included comprise only a minority $(5 \%)$ of the total phylogenetic characters, ensuring a degree of independence between the two character sets.

Determination of polarity of character morphs for assigning peramorphic and paedomorphic conditions was performed with reference to the observed ontogenetic trajectories of extinct and extant species. The most extensive work on xiphosurid development and ontogeny has focused on the extant American species Limulus polyphemus, with studies of embryonic (Scholl 1977; Sekiguchi et al. 1982; Sekiguchi 1988; Shuster and Sekiguchi 2003; Haug and Rötzer 2018a) and postembryonic
(Sekiguchi et al. 1988a,b; Shuster and Sekiguchi 2003) ontogeny supplemented by detailed studies of the early development of the thoracic opercula and book gills (Farley 2010) and compound lateral eyes (Harzsch et al. 2006). Comparatively few studies of the extant Asian species' ontogenies exist; those few that do focus on Tachypleus tridentatus (Sekiguchi et al. 1982, 1988a,b; Sekiguchi 1988), often via direct comparison with the development of Limulus.

Ontogenetic data also exist for a number of extinct taxa from across the xiphosurid phylogeny. The bellinurines Euproops danae and Euproops sp., from the Carboniferous of the United States and Germany, respectively, have been subject to detailed study of their postlarval development (Schultka 2000; Haug et al. 2012; Haug and Rötzer 2018b; Tashman et al. 2019). Ontogenetic data have also been reported from the bellinurine Alanops magnificus, known from the Carboniferous Montceau-les-Mines Konservat-Lagerstätte in France, a species considered to demonstrate a paedomorphically derived adult morphology (Racheboeuf et al. 2002). Bellinurine embryonic larvae preserved within egg clutches have also been reported from the Carboniferous of Russia and assigned to the newly erected species Xiphosuroides khakassicus (Shpinev and Vasilenko 2018), which probably represent the larvae of an existing species of Bellinurus. Outside of the bellinurines, juvenile and adult individuals of the paleolimulid Paleolimulus kunguricus, from the Permian of Russia have been described (Naugolnykh 2017). Subadult and adult stages have also been differentiated among the available material of the Cretaceous tachypleine Tachypleus syriacus from the Hâqel and Hjoûla Konservat-Lagerstätten of Lebanon (Lamsdell and McKenzie 2015), while the Cretaceous mesolimulid Mesolimulus tafraoutensis from the Gara Sbaa Konservat-Lagerstätte of Morocco is known from juvenile material (Lamsdell et al. 2020).

This diversity in phylogenetic sampling of xiphosurid ontogeny reveals a number of consistent trends in horseshoe crab development across their evolutionary history that can still be observed in the ontogeny of modern species (Fig. 4). These evolutionarily conserved 
1. Body size

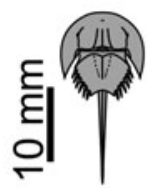

$-1$

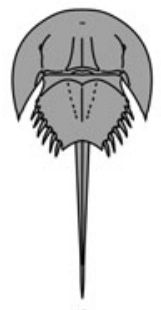

0

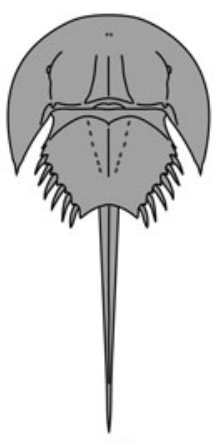

$+1$
2. Eye spines

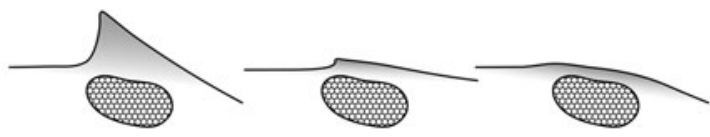

$-1$

0

$+1$

\section{Eye position}

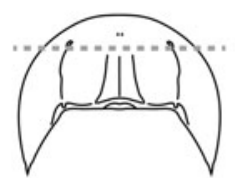

$-1$

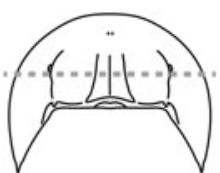

0

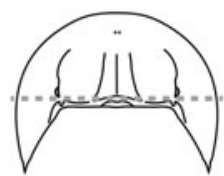

$+1$

\section{Eye size}

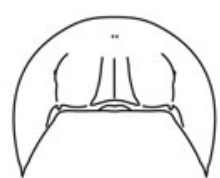

$-1$

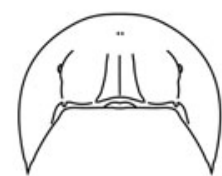

0

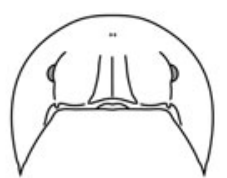

$+1$
5. Ophthalmic ridge expression

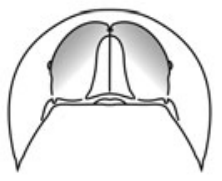

$-1$

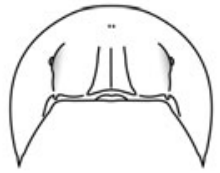

0

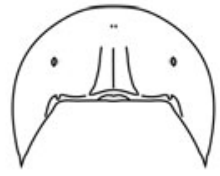

$+1$
7. Genal spine position

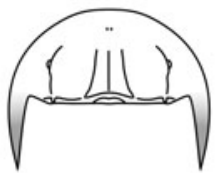

$-1$

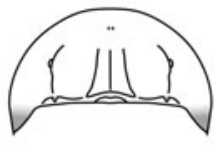

0

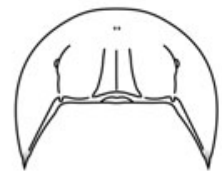

$+1$
6. Ophthalmic spines

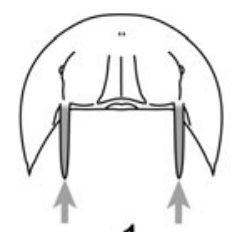

$-1$

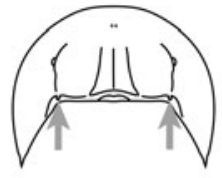

0

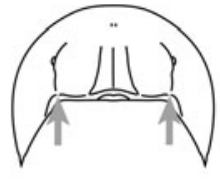

$+1$

8. Genal spine angle

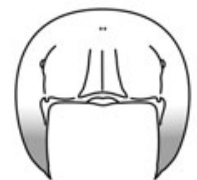

$-1$

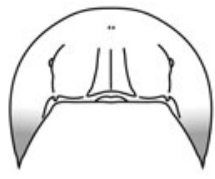

0

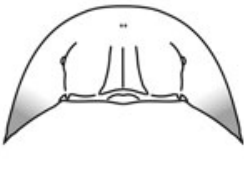

$+1$
9. Genal spine length

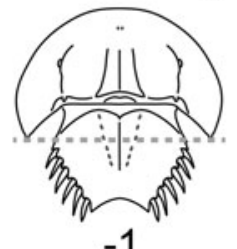

$-1$

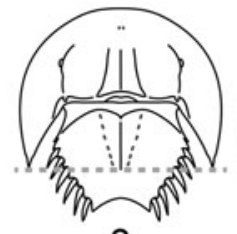

0

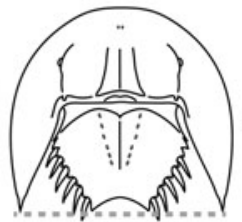

$+1$

10. Limb length

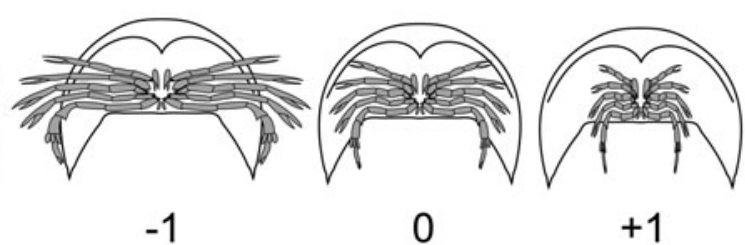

FIGURE 2. Heterochronic characters coded for Xiphosura encompassing aspects of overall body size and prosomal morphology, showing paedomorphic (-1), neutral (0), and peramorphic (+1) conditions. A character unavailable for coding in a species is considered missing data (?) and does not contribute to the species score. 
11. Thoracetron shape

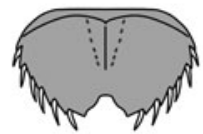

$-1$

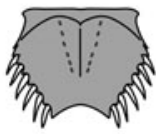

0

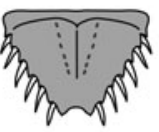

$+1$

12. Thoracetron tergites

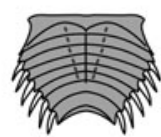

$-1$

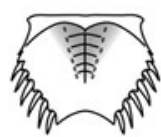

0

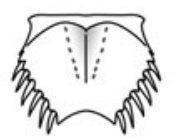

$+1$
13. Free lobe segment

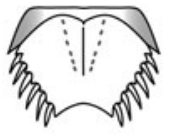

$-1$

15. Epimera

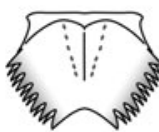

$-1$

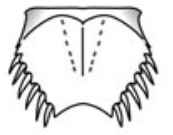

0

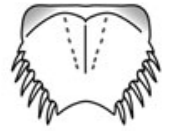

$+1$

14. Axial/subaxial nodes

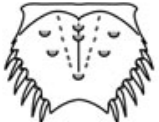

$-1$

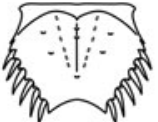

0

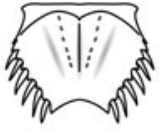

$+1$

16. Movable spines

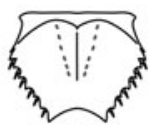

$-1$

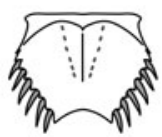

0

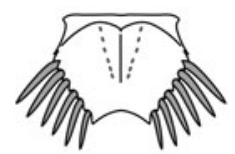

$+1$
17. Pretelson epimera

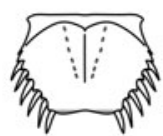

$-1$

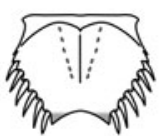

0

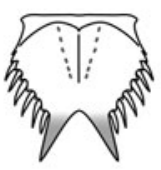

$+1$
18. Opercula

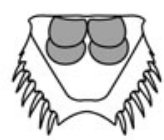

$-1$

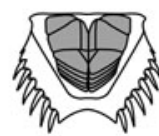

0

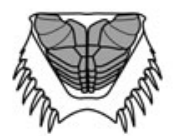

$+1$
19. Thoracetron doublure
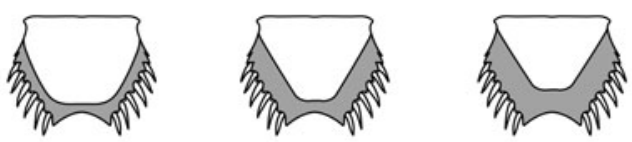

20. Telson length
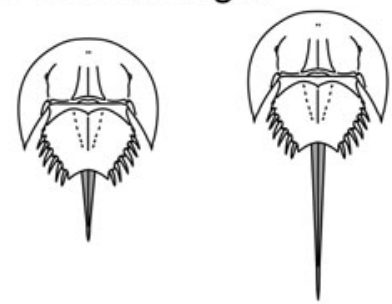

$-1$

0

0

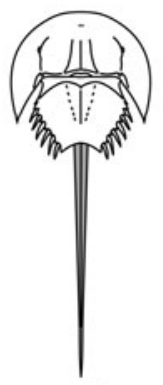

$+1$

FIGURE 3. Heterochronic characters coded for Xiphosura encompassing aspects of thoracetron and telson morphology, showing paedomorphic (-1), neutral (0), and peramorphic (+1) conditions. A character unavailable for coding in a species is considered missing data (?) and does not contribute to the species score.

ontogenetic trends include a progressive reduction in expression of the prosomal ophthalmic ridge from the larval form through to the adult, a relative decrease in the length of the 
TABLE 1. Character traits used in the heterochronic character matrix, detailing the ancestral or base condition and the peramorphic and paedomorphic expression of each. Diagrammatic representations of each character are shown in Figs. 2 and 3.

\begin{tabular}{|c|c|c|c|c|}
\hline & \multirow[b]{2}{*}{ Trait } & \multicolumn{3}{|l|}{ Condition } \\
\hline & & Paedomorphic & Neutral & Peramorphic \\
\hline 1. & Body size & Decreased & $2-5 \mathrm{~cm}$ & Increased \\
\hline 2. & Eye spines & Expressed & Vestigial projection & Suppressed \\
\hline 3. & Eye position & Anterior & Central & Posterior \\
\hline 4. & Eye size & Reduced & Moderate & Enlarged \\
\hline 5. & $\begin{array}{l}\text { Ophthalmic ridge } \\
\text { expression }\end{array}$ & Fully expressed & Laterally expressed & Totally suppressed \\
\hline 6. & Ophthalmic spines & Elongated & Vestigial & Totally suppressed \\
\hline 7. & Genal spine position & Anterior to intragenal notch & At carapace posterior & $\begin{array}{l}\text { Distally on pleural } \\
\text { projections }\end{array}$ \\
\hline 8. & Genal spine angle & Posterior & Intermediate & Lateral \\
\hline 9. & Genal spine length & Reduced & Half total prosomal shield length & Elongated \\
\hline 10. & Limb length & Elongated & To carapace margin & Shortened \\
\hline 11. & Thoracetron shape & Semicircular & Subquadrate & Triangular \\
\hline 12. & Thoracetron tergites & Fully expressed & Axially expressed & Suppressed \\
\hline 13. & Free lobe segment & Separate segment & Laterally free & Laterally reduced \\
\hline 14. & Axial/subaxial nodes & Enlarged & Subdued & Suppressed \\
\hline 15. & Epimera & Elongated & Length equal to width at base & Reduced \\
\hline 16. & Movable spines & Reduced & Length $\sim 2 \times$ width at base & Elongated \\
\hline 17. & Pretelson epimera & Reduced & Length equal to width at base & Elongated \\
\hline 18. & Opercula & $\begin{array}{l}\text { Reduced number, vestigial } \\
\text { exopod only }\end{array}$ & $\begin{array}{l}\text { Fully expressed exopod, reduced } \\
\text { endopod }\end{array}$ & $\begin{array}{l}\text { Enlarged, increased } \\
\text { endopod expression }\end{array}$ \\
\hline 19. & Thoracetron doublure & Narrowed & Width $\sim 40 \%$ that of thoracetron & Expanded \\
\hline 20. & Telson length & Shortened & $\begin{array}{l}\text { Approximately half total body } \\
\text { length }\end{array}$ & Elongated \\
\hline
\end{tabular}

prosomal appendages, a reduction in expression of the free lobe segment, an increase in the number and complexity of opisthosomal opercula, and an increase in the relative length of the telson compared with the body. It is these traits, alongside other observed consistent trends in xiphosuran ontogeny, that were incorporated into the heterochronic character matrix.

Phylogenetic Analysis.-A phylogenetic framework for Xiphosura was constructed using an expanded version of the chelicerate character matrix from Lamsdell (2016), which itself draws on matrices presented in Lamsdell (2013), Selden et al. (2015), Lamsdell and McKenzie (2015), and Lamsdell et al. (2015). The resulting matrix comprises 256 characters coded for 153 taxa and is available in the online MorphoBank database (O'Leary and Kaufman 2012) under the project code p2606 (accessible from http://morphobank.org/permalink/? P2606) as well as in the Supplementary Material. Sampling of Xiphosurida within the matrix was increased by six, incorporating Limulus woodwardi (Watson 1909) and the newly described Limulitella tejraensis (Błażejowski et al. 2017),
M. tafraoutensis (Lamsdell et al. 2020), P. kunguricus (Naugolnykh 2017), Paleolimulus woodae (Lerner et al. 2016), and Vaderlimulus tricki (Lerner et al. 2017). Three taxa were removed from the matrix: Anacontium brevis, which is a synonym of the co-occurring Anacontium carpenteri (Anderson 1997); Liomesaspis leonardensis, which is poorly preserved and lacks diagnostic characters separating it from Liomesaspis laevis (see Tasch 1961); and Willwerathia laticeps, which may not be a chelicerate (Lamsdell 2019). In total, 54 Xiphosura (sensu Lamsdell 2013, 2016) were included, and it is these taxa that were the focus of subsequent analyses of heterochrony and ecological affinity, with the remaining 99 taxa within the matrix serving to adequately root and demonstrate the monophyly of the xiphosuran clade. Additionally, the character coding for Yunnanolimulus luopingensis was updated to incorporate information from recently described specimens exhibiting exceptional preservation ( $\mathrm{Hu}$ et al. 2017). Four new characters were also added to the matrix, encompassing cardiac lobe width (character $32)$, the cardiac lobe bearing a median cardiac 


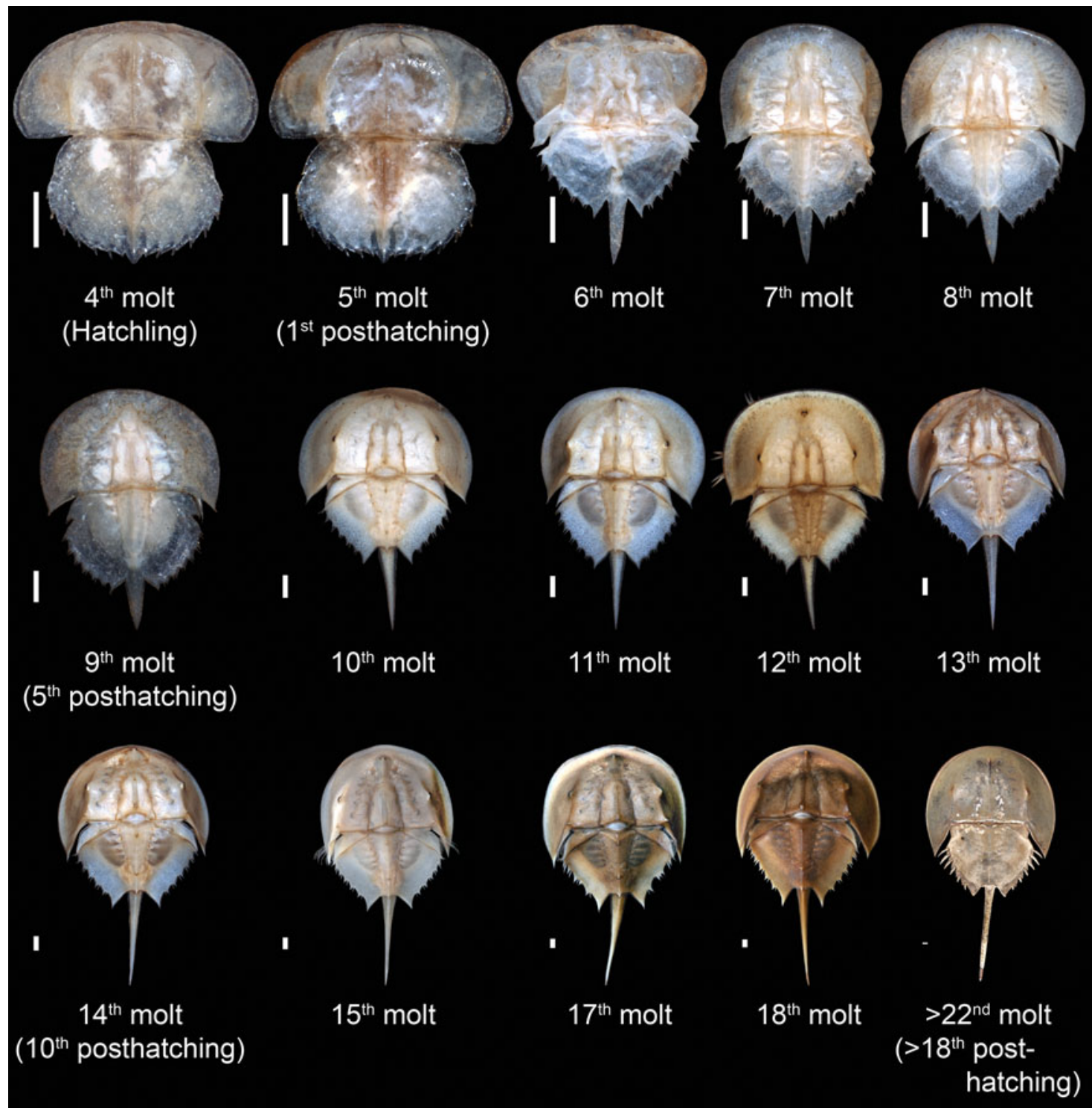

FIGURE 4. Ontogenetic sequence of Limulus polyphemus from the Yale Peabody Museum teaching collection, beginning with the hatchling (fourth molt) and proceeding to the adult (post-22 ${ }^{\text {nd }}$ molt, which corresponds to the $18^{\text {th }}$ posthatching molt). The final molt is represented by specimen YPM IZ 070174. The size of each instar has been standardized to more clearly demonstrate changes in relative morphological proportions. Scale bars, $1 \mathrm{~mm}$.

ridge with rounded cross section (character 38 ), the occurrence of a genal groove (character 45), and the course and extent of the genal groove (character 46). Morphological terminology for character definitions follows Selden and Siveter (1987) and Lamsdell (2013).

Tree inference was performed using Bayesian statistical analysis, which has been shown to outperform maximum parsimony analyses of simulated data (Wright and Hillis 2014; O'Reilly et al. 2016; Puttick et al. 2017, 2019), although tree topologies derived from empirical data analyzed under parsimony methods exhibit higher stratigraphic congruence than those retrieved from Bayesian analysis (Sansom et al. 2018). Bayesian inference was performed using Markov chain Monte Carlo analyses as implemented in MrBayes 3.2.6 (Huelsenbeck 
and Ronquist 2001), with four independent runs of 100,000,000 generations and four chains each under the maximum-likelihood model for discrete morphological character data $(\mathrm{Mkv}+$ $\Gamma$; Lewis 2001), with gamma-distributed rate variation among sites. All characters were treated as unordered and equally weighted (Congreve and Lamsdell 2016). Trees were sampled with a frequency of every 100 generations, resulting in 1,000,000 trees per run. The first 25,000,000 generations (250,000 sampled trees) of each run were discarded as burn-in, and the $50 \%$ majority rule consensus tree was calculated from the remaining 750,000 sampled trees across all four runs; this represents the optimal summary of phylogenetic relationships given the available data (Holder et al. 2008). Posterior probabilities were calculated from the frequency at which a clade occurred among the sampled trees included in the consensus tree.

Additionally, maximum parsimony analysis was performed using TNT (Goloboff et al. 2008) (made available with the sponsorship of the Willi Hennig Society) to test for topological congruence between Bayesian and parsimony methods. The search strategy employed 100,000 random addition sequences with all characters unordered and of equal weight (Congreve and Lamsdell 2016), each followed by tree bisection-reconnection branch swapping (the mult command in TNT). Jackknife (Farris et al. 1996), bootstrap (Felsenstein 1985), and Bremer (Bremer 1994) support values were also calculated in TNT and the ensemble Consistency, Retention and Rescaled Consistency Indices were calculated in Mesquite 3.02 (Maddison and Maddison 2018). Bootstrapping was performed with $50 \%$ resampling for 1,000 repetitions, while jackknifing was performed using simple addition sequence and tree bisectionreconnection branch swapping for 1,000 repetitions with $33 \%$ character deletion.

Ecological Affinity.-Previous work by Kiessling and Aberhan (2007) and Hopkins (2014) has set out a series of standard environmental categories for organisms found in marine environments; latitudinal occupation, substrate preference, bathymetry, and reef association. For the present study, however, a novel characteristic is considered: salinity. Previous work has shown that horseshoe crabs invaded nonmarine environments multiple times over their evolutionary history (Lamsdell 2016), a transition associated with a variety of biomechanical and physiological challenges (Lamsdell in press), and it is these macroevolutionary events that comprise the focus of the work herein. As with the characteristics of Kiessling and Aberhan (2007) and Hopkins (2014), salinity is reduced to a binary variable, and species are assigned either a marine or nonmarine (including freshwater and deltaic/transitional marginal-marine environments with a large amount of continental flora and fauna) affinity. The ecological affinity for each taxon was estimated through the modified method of Miller and Connolly (2001). This is a departure from Hopkins (2014), who implemented a refined version of the Bayesian estimation of affinity developed by Simpson and Harnik (2009), which has traditionally been applied to higher taxa (e.g., genera). The drawback of applying the Bayesian estimation method to species data is that it requires multiple samples; Simpson and Harnik (2009) only considered genera with at least four occurrences. This is impossible for many species in the fossil record, particularly unmineralized marine organisms (which include horseshoe crabs), the majority of which are known solely from single localities - representing only a single occurrence. In contrast, the method of Miller and Connolly (2001) simply calculates the affinity of a taxon for a given environment as the number of occurrences within the environment divided by the total number of occurrences, resulting in a metric ranging from 0 to 1 ; when combined, the value of the metric for each of the two possible affinities and no clear affinity will always sum to 1 . The advantage of this method is that it can operate with only a single observation, with the drawback that lower sample sizes increase the chances of a false positive of ecological affinity. However, species tend to have a narrow range of habitat preferences (Saupe et al. 2014, 2015), thereby reducing the chance of occurrences outside their preferred environments; when species do have broader habitat preferences, they also tend to have broader geographic ranges, increasing the probability of fossilization and 
thereby increasing the available sample size, reducing the chance of false positives.

The resulting metrics for ecological affinity were interpreted as any single value $>0.5$ indicating a preference for that environment. When no single environment scored $>0.5$, the taxon was considered to exhibit no affinity. Ties (an instance where the highest-scoring environment achieved a 0.5) were also considered an indication of no affinity. In practice, as the majority of horseshoe crab species are known from only one or a handful of localities, most species showed a clear ecological affinity (see Supplementary Material).

Phylogenetic Paleoecology.-The emergent field of phylogenetic paleoecology leverages phylogenetic information to assess the longterm evolutionary significance of ecological trends within lineages through the synthesis of phylogenetic theory and quantitative paleoecology (Lamsdell et al. 2017). Using the historical phylogenetic and ecological framework, it is possible to test for phylogenetic or ecological signal in the distribution of heterochronic weightings, thereby accounting for the possible influence of both the genealogical and ecological biological hierarchies (Congreve et al. 2018).

The phylogenetic framework also permits for the estimation of the ancestral conditions of both morphological and ecological characteristics. To determine the number of transitions between marine and nonmarine environments, the ecological affinity of each species as determined above was mapped onto the resulting phylogenetic tree and parsimony-based ancestral state reconstruction performed in Mesquite 3.02 (Maddison and Maddison 2018). The inferred ancestral ecological affinities were used to polarize the internal nodes of the tree, thereby establishing whether the ecological affinities of tip species represent inherited habitat preferences or are the result of a shift in the occupied niche.

Multivariate statistical tests (permutational multivariate analysis of variance [PERMANOVA] using the Euclidian distance measure) were performed in the statistical software package PAST (Hammer et al. 2001) and using the adonis function in the $\mathrm{R}$ ( $\mathrm{R}$ Core Team 2018) package vegan (Oksanen et al. 2019) to ascertain the statistical significance of differences in heterochronic weightings across ecological affinities and phylogenetic clades. Several analyses were performed: comparison between marine and nonmarine habitats, comparison between clades, and a test of the interaction between clade and habitat categories. For the comparison between marine and nonmarine habitats, all species were included in the analysis. However, for analyses that required the assignment of species to clades, only species assignable to Bellinurina, Paleolimulidae, Austrolimulidae, or Limulidae were included. This resulted in the exclusion of Lunataspis aurora and Kasibelinurus amoricum (stem Xiphosurida), Bellinuroopsis rossicus and Rolfeia fouldenensis (stem Limulina), and Valloisella lievinensis (stem Limulidae), as their inclusion would necessitate the formulation of unnatural, paraphyletic "groups" that possess no evolutionary cohesion and could serve to bias analyses. Significance was estimated by permutation across groups with 10,000 replicates, including Bonferroni correction to correct for multiple comparisons in the case of comparison between clades.

To test whether the distributions of species' heterochronic weightings within clades exhibit directional trends, Spearman's (1904) rank correlation coefficient $\rho$, calculated using the cor.test function in $\mathrm{R}$ (R Core Team 2018), was used to compare the heterochronic weighting of observed taxa within a clade to their distance from the root of the clade. A statistically significant $\rho$, in combination with a statistically significant clade heterochronic weighting [Hw], was considered evidence of a concerted heterochronic trend within the clade. The distance of a species from the root of the clade was determined using the cladistic rank method (Gauthier et al. 1988; Norell and Novacek 1992a,b; Norell 1993; Benton and Storrs 1994; Benton and Hitchin 1997; Carrano 2000, 2006; Wagner and Sidor 2000; Poulin 2005; Prado and Alberdi 2008; Huttenlocker 2014). Cladistic rank is determined by counting the sequence of primary nodes in a cladogram from the basal node to the ultimate node (Fig. 5). The main axis of the cladogram is defined as the internal branch supporting the most inclusive clade after each bifurcation. Smaller offshoot clades 
Taxa

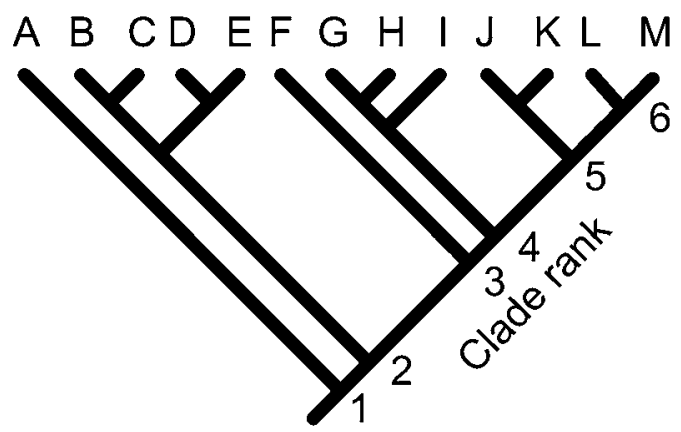

Source tree

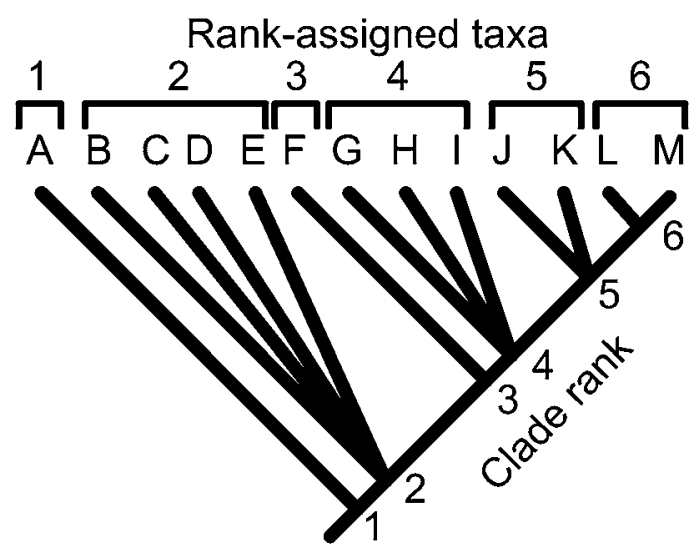

Ranked tree

FIGURE 5. Example of the method for assigning taxa to clade ranks for Spearman's rank correlation.

are reduced to polytomies for the purpose of assigning a clade rank, with each constituent species within a polytomy receiving the same rank. The assignment of equal rank to all constituents of an offshoot clade is a conservative approach that ensures any revealed trend is the majority pattern demonstrated by the most inclusive clades within the cladogram, without biasing the analysis through exclusion of taxa located in offshoot clades. This was done for each of the four main xiphosurid clades: Bellinurina, Paleolimulidae, Austrolimulidae, and Limulidae.

\section{Results}

Analysis of the phylogenetic character matrix resulted in Bayesian inference and parsimony optimality criteria retrieving a concordant tree topology, with the strict parsimony consensus of six most parsimonious trees having an identical hypothesis of xiphosuran relationships to the Bayesian majority rule consensus (Fig. 6; for details of the parsimony tree and the full Bayesian tree, see Supplementary Material). The phylogenetic topology, while broadly consistent with those of previous analyses (Lamsdell 2013, 2016; Lamsdell and McKenzie 2015), is more stratigraphically congruent due to movement in the placement of K. amoricum, 'Kasibelinurus' randalli, and Casterolimulus kletti. Previously resolving as a paraphyletic grade at the base of Xiphosura, K. amoricum now resolves as the sister taxon to the clade comprising the two suborders Limulina and Bellinurina, while 'Kasibelinurus' randalli resolves at the base of Bellinurina. This leaves L. aurora, the sole described Ordovician species, as the sister taxon to all other Xiphosura. Casterolimulus, previously resolved as the sole post-Triassic representative of Austrolimulidae, now forms a clade with Victalimulus within Limulidae. Victalimulus and Casterolimulus are both Cretaceous taxa known from nonmarine environments, and the notion that they share common ancestry has been suggested previously (Lamsdell in press). The internal relationships of the bellinurines and limulids are also better resolved, and a sister clade to the xiphosuran crown group (composed of Tachypleinae and Limulinae) comprising Mesolimulus, 'Limulitella' vicensis, 'Limulus' woodwardi, Victalimulus, and Casterolimulus is recognized for the first time.

The distribution of environmental affinity across the phylogeny of Xiphosura supports previous assertions that the group has invaded nonmarine environments from the marine realm multiple times over the course of its evolutionary history (Lamsdell 2016). However, whereas previous estimates suggested that the transition from a marine to nonmarine environmental affinity had occurred at least five times 


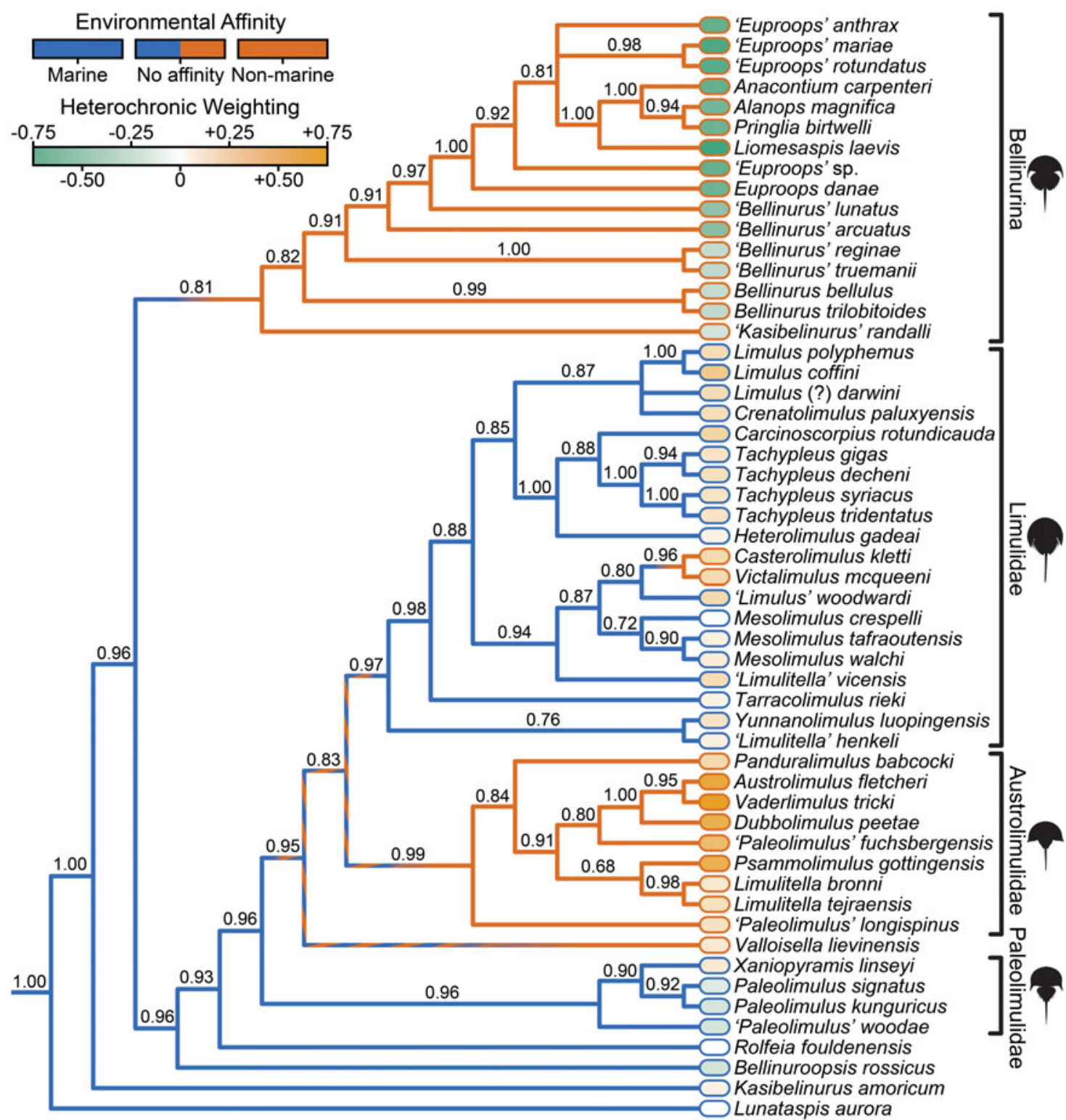

FIGURE 6. Bayesian phylogeny of xiphosurids showing environmental affinity of salinity and heterochronic weighting mapped onto the tree. Environmental affinity is indicated on the branches (blue, marine; brown, nonmarine), heterochronic weighting is shown at the tips alongside the taxon names through heat-map shading (green, more paedomorphic; orange, more peramorphic). Bayesian posterior probabilities are shown below each node. The clades shown in Figs. 7 and 8 are labeled alongside the tree.

during xiphosuran evolution, the present results indicate such a transition has occurred only four, or potentially as few as three, times (Fig. 6). Ancestral state reconstruction demonstrates that a marine affinity is plesiomorphic for Xiphosura and that shifts to a nonmarine affinity occurred for the clades Bellinurina and
Austrolimulidae, as well as Valloisella and the sister taxa Victalimulus and Casterolimulus. While Bellinurina and the Victalimulus/ Casterolimulus clade are clearly derived from marine-dwelling lineages that subsequently transitioned to nonmarine environments, the situation for Valloisella and the austrolimulids 
is less clear. Due to the tree topology, with $\mathrm{Val}$ loisella - a nonmarine xiphosurid - resolving as sister taxon to a large clade divided between the predominantly marine Limulidae and the nonmarine Austrolimulidae, ancestral state reconstruction is unable to determine a clear environmental affinity for the internal nodes between Limulidae, Austrolimulidae, and $\mathrm{Val}$ loisella. These results infer a number of potential evolutionary scenarios. One possibility is that Valloisella and Austrolimulidae independently transitioned to nonmarine environments and a marine affinity is plesiomorphic for Limulidae. Alternatively, Valloisella, Austrolimulidae, and Limulidae may all be derived from fully euryhaline ancestors that genuinely have no environmental affinity and occupied both marine and nonmarine environments; in this case, the transition to a nonmarine affinity in Valloisella and Austrolimulidae, and a marine affinity in Limulidae, would be the result of a reduction in their ancestral occupied niche. Finally, it is possible that the transition to nonmarine environments occurred in the ancestors of Valloisella, Austrolimulidae, and Limulidae and that a nonmarine affinity is therefore plesiomorphic for all three taxa, with Limulidae having undergone a subsequent reversal to reoccupy marine environments.

Heterochronic weightings are unevenly distributed across the phylogeny, with more extreme (i.e., higher positive or negative) values occurring among taxa with a nonmarine environmental affinity. This distinction is borne out statistically, with PERMANOVA tests showing that the variance of heterochronic weightings of all species occupying marine environments is significantly distinct from that of those occupying nonmarine environments (Table 2). Statistically significant differences also separate the heterochronic
TABLE 2. One-way permutational multivariate analysis of variance $\left(F_{(1,53)}=4.197, \eta^{2}=0.075, p=0.0424\right), 10,000$ permutations, Euclidean distance measure. Value in regular font is the $p$-value, value in italics is the raw $F$-value. Total sum of squares $=5.120$, within-group sum of squares $=4.737$, between-group sum of squares $=0.383$.

\begin{tabular}{lll}
\hline \hline & Marine & Nonmarine \\
\hline Marine & - & 4.197 \\
Nonmarine & 0.045 & - \\
\hline
\end{tabular}

weightings of the xiphosuran clades Bellinurina, Paleolimulidae, Austrolimulidae, and Limulidae (Table 3). Environmental affinity and phylogenetic relatedness therefore both influence heterochronic weightings; however, there appears to be no interaction between the two factors, indicating that they exhibit conflicting signals and do not covary (Table 4).

Comparing the heterochronic weightings of Bellinurina, Paleolimulidae, Limulidae, and Austrolimulidae to the distribution of randomized heterochronic weightings reveals the heterochronic weightings of Bellinurina, Austrolimulidae, and Limulidae to be significantly different from what would be expected from random, while that of Paleolimulidae falls within what could be explained from a random distribution (Fig. 7). Interestingly, Spearman's rank correlation (Fig. 8), indicates directional trends in heterochronic weighting within Austrolimulidae and Bellinurina, but no significant trend within Limulidae or Paleolimulidae. The heterochronic weightings of Bellinurina and Austrolimulidae show a consistent directional trend as demonstrated by locally estimated scatterplot smoothing (LOESS) regression (although Bellinurina do undergo a slight shift in trajectory among their highest-ranked clades), while Paleolimulidae and Limulidae exhibit random directional shifts across the phylogeny. This distinction is potentially

TABLE 3. One-way permutational multivariate analysis of variance $\left(F_{(3,49)}=73.87, \eta^{2}=0.83, p=0.0001\right)$ excluding stem taxa, 10,000 permutations, Euclidean distance measure. Values in regular font are Bonferroni corrected $p$-values, those in italics are raw $F$-values. Total sum of squares $=5.088$, within-group sum of squares $=0.8588$, between-group sum of squares $=4.2292$.

\begin{tabular}{lllll}
\hline \hline & Bellinurina & Paleolimulidae & Austrolimulidae & Limulidae \\
\hline Bellinurina & - & 14.79 & 113.5 & 175.4 \\
Paleolimulidae & 0.0024 & - & 16.94 & 20.44 \\
Austrolimulidae & 0.0006 & 0.0204 & - & 0.0018 \\
Limulidae & 0.0006 & 0.0036 & - & 20.79 \\
\hline
\end{tabular}


TABLE 4. Two-way permutational multivariate analysis of variance excluding stem taxa, 10,000 permutations, Euclidean distance measure.

\begin{tabular}{lllrrl}
\hline \hline $\begin{array}{l}\text { Source of } \\
\text { variation }\end{array}$ & $\begin{array}{l}\text { Sum of } \\
\text { squares }\end{array}$ & df & $\begin{array}{c}\text { Mean } \\
\text { squares }\end{array}$ & $F$ & $p$ \\
\hline Habitat & 0.46075 & 1 & 0.46075 & 10.155 & 0.0001 \\
Clade & 3.77600 & 3 & 1.25867 & 27.742 & 0.0001 \\
Interaction & 0.00005 & 3 & $<0.00002$ & $<0.0004$ & 1 \\
Residual & 1.86020 & 41 & 0.04537 & & \\
Total & 5.08770 & 48 & & & \\
\hline
\end{tabular}

borne out in the position of the observed heterochronic weightings relative to the randomized distribution of heterochronic weightings: the observed weightings for Bellinurina and Austrolimulidae sit far outside the randomized distribution, expressing a value that does not occur within the randomized weights.
In comparison, the observed heterochronic weighting for Limulidae falls within the tail of the randomized distribution, with a value equal to that of a set of those retrieved from the randomizations.

\section{Discussion}

Shifts in ecological affinity correlate with changes in evolutionary regime in Xiphosura. Clades that invade nonmarine environments exhibit distinct differences in the prevalence of heterochronic traits in comparison to those that inhabit the marine realm (Fig. 6), with Austrolimulidae demonstrating increased prevalence of peramorphy, while paedomorphy is prevalent among Bellinurina (Fig. 7). Paedomorphic traits have long been recognized in bellinurines

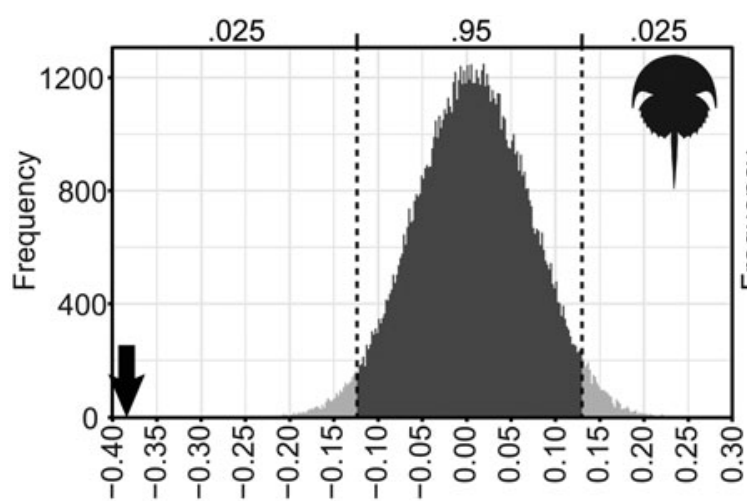

Bellinurina Heterochronic Weighting

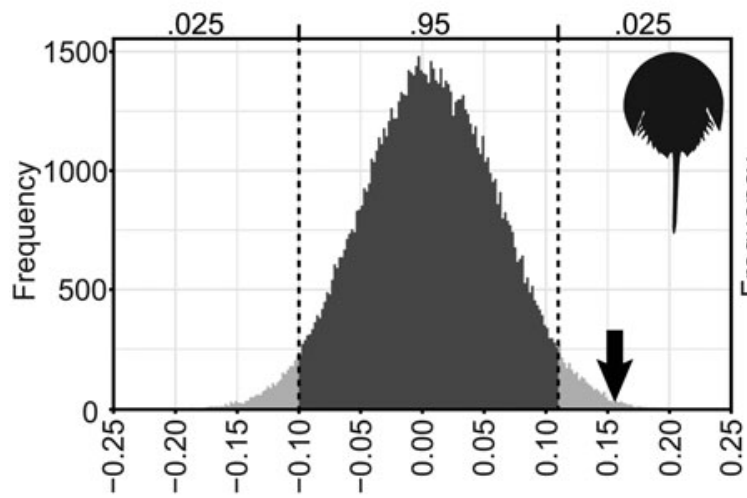

Limulidae Heterochronic Weighting

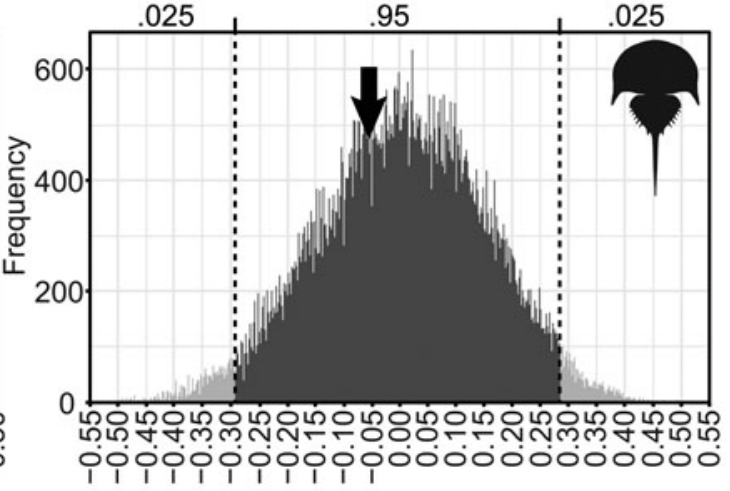

Paleolimulidae Heterochronic Weighting

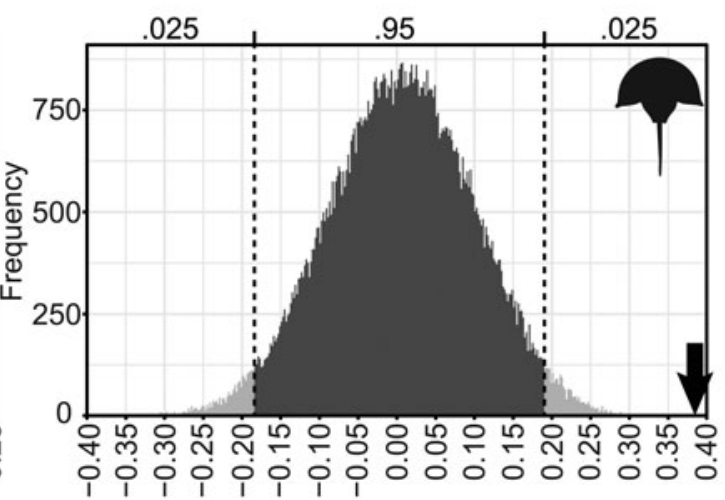

Austrolimulidae Heterochronic Weighting

FIGURE 7. Histograms showing the distribution of randomized heterochronic weightings across 100,000 permutations for Bellinurina, Paleolimulidae, Limulidae, and Austrolimulidae. The actual heterochronic weightings of the clades, derived using characters shown in Figs. 2 and 3, are indicated by the black arrows. Weightings in either tail of the distribution are considered to be more extreme than would be expected from random. The negative tail indicates the occurrence of paedomorphosis, the positive tail indicates peramorphosis. 

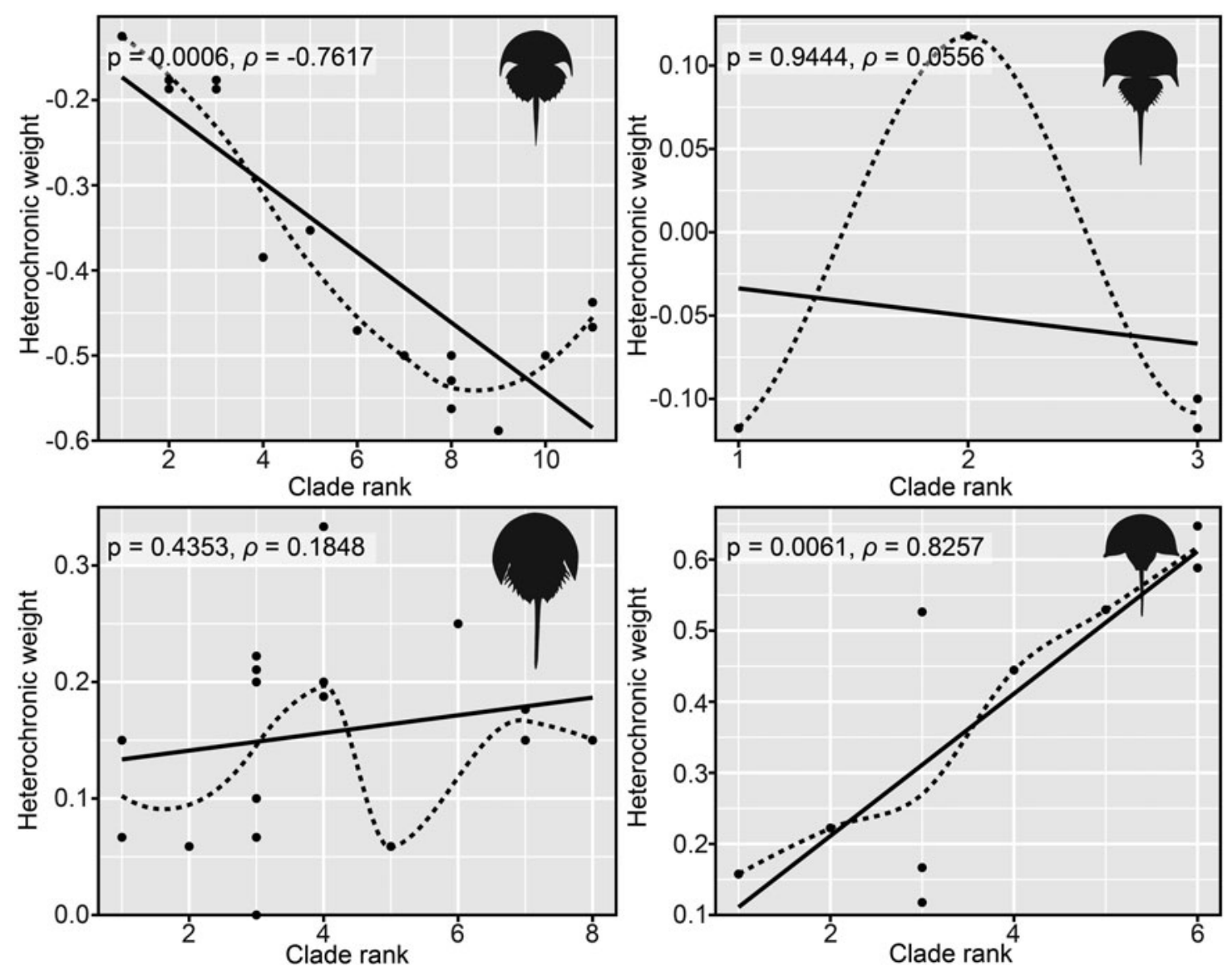

FIGURE 8. Graphs showing distribution of heterochronic weightings along clade rank for Bellinurina, Paleolimulidae, Limulidae, and Austrolimulidae. Each plot displays a solid linear regression line and a dashed LOESS regression line. A negative slope indicates a general paedomorphic trend, while a positive slope is representative of a peramorphic trend. The results of Spearman's rank correlation, both in terms of statistical significance and raw $\rho$, are shown at the top of each graph.

(Haug et al. 2012; Lamsdell in press), including their retention of long, gracile prosomal appendages into adulthood; visible opisthosomal segmentation; and elongated dorsal prosomal shield spines. Austrolimulids, meanwhile, develop elongate and splayed prosomal genal spines; reduce the size of their opisthosomal tergopleura; and exhibit enlarged, posteriorly positioned lateral eyes - all of which are recognized as peramorphic conditions herein. Interestingly, lineages that make the transition to nonmarine environments demonstrate concerted and enduring heterochronic trends (Fig. 8) that persist for millions of years, with species progressively exhibiting an increasingly greater number of paedomorphic (in Bellinurina) or peramorphic (in Austrolimulidae) traits. It seems that shifts in environmental occupation set these lineages along a heterochronic trajectory resulting in a directional bias (Gould 1982), whereby changes in the timing or rate of development produce innovative morphologies, the selection of which-mediated by the environment - result in increasingly specialized phenotypes. Heterochronic processes are known to be one of the primary ways by which morphological innovation (sensu Erwin 2015a, 2017) occurs (McNamara and McKinney 2005; McNamara 2012; Colangelo et al. 2019), and it is the nonmarine xiphosurans that contribute the most to xiphosuran disparity and occupy novel regions of morphospace (Lamsdell 2016). 
It is notable that only rarely do either of the heterochronic trends observed here show any indication of heterochronic reversals and that in both cases the trend is associated with a marked shift in diversity dynamics, with Bellinurina increasing in diversity before rapidly going extinct and Austrolimulidae exhibiting decreased rates of speciation and a lower diversity even in relation to other Xiphosura (Lamsdell 2016, in press). The combination of limited reversal and shift in diversity dynamics suggests that these directional trends may represent macroevolutionary ratchets (trends where reversals are rare and ultimately result in increased extinction risk or a decrease in rates of origination: Van Valkenburgh 1991, 1999; Van Valkenburgh et al. 2004), although whether this is due to consistent environmental pressure or some inherent property of the developmental processes operating is unclear. Numerous consistent peramorphic and paedomorphic evolutionary trends associated with environmental gradients-termed peramorphoclines and paedomorphoclines (McNamara 1982), or more generally heteroclines (McKinney 1999), although these terms conflate process (heterochrony) and evolutionary outcome (directional bias or macroevolutionary ratcheting) — have been recognized in the fossil record (McNamara 1982, 1986, 1988; Simms 1988; Korn 1995; Crônier et al. 1998; McKinney 1999; Poty 2010; Fernandez-Lopez and Pavia 2015). Most described heterochronic trends do not exhibit heterochronic reversals, with only a few notable exceptions (Gerber 2011), although it should be noted that none of these studies were performed within a phylogenetic framework. It has previously been suggested that concerted heterochronic trends are always controlled by environmental factors (McKinney 1986, 1988); however, subsequent studies have documented heterochronic trends occurring apparently independently of any environmental gradient (Breton 1997). In the present study, xiphosurans possibly undergo one reversal in environmental affinity, with the ancestors of the predominantly marine Limulidae potentially having a nonmarine or mixed environmental affinity (Fig. 6). The ramifications of this are twofold. First, it would suggest that xiphosurans survived the end-Permian mass extinction by occupying nonmarine environments and returned to the marine realm during the subsequent recovery, a possibility first suggested by Błażejowski et al. (2017). Second, Limulidae display on average more positive heterochronic weightings than other marine taxa (Fig. 7), although these peramorphic traits do not manifest as part of a concerted trend (Fig. 8) as they do in the limulid nonmarine sister group, Austrolimulidae, which is characterized by extreme peramorphism. This opens up the possibility that, if limulids have reoccupied marine environments from an ancestral nonmarine habitat, the elevated occurrence of peramorphic character conditions in the clade may be a relict of the peramorphic trajectory that continued in austrolimulids. If this were to be the case, it would suggest that returning to marine environments stopped the heterochronic bias in limulids, and perhaps most interestingly, that the changes the lineage had undergone while occupying nonmarine environments were not subsequently reversed.

The exact mechanism by which heterochrony operated in the cases observed here is uncertain. It is notoriously difficult (arguably impossible) to discern between changes in timing and changes in rate of development without detailed ontogenetic sequences of consecutive species (Gould 1988; Jones 1988; McKinney 1988; Allmon 1994; McNamara and McKinney 2005; Bardin et al. 2017). Nevertheless, it is possible to recognize broad peramorphic and paedomorphic trends. Why these processes unfolded in a ratchet-like fashion is also unclear. Classical natural selection (Darwin 1859) may explain the evolution of increasingly unusual morphologies; however, it is unclear whether these morphologies are truly specialized or simply bizarre. Another possibility among the Bellinurina is that physiological changes required in order for xiphosurans to tolerate low-salinity environments for extended periods of time may have been accomplished through the retention of larval physiology into adulthood (Lamsdell in press). The larvae of modern horseshoe crabs are extremely tolerant of salinities lower than 35\% (Shuster 1982; Ehlinger and Tankersley 2007; Botton et al. 2010), and paedomorphic processes permitting 
the maintenance of this tolerance in adults may have also resulted in the retention of larval morphological characteristics. The broad, shallow prosomal carapaces of austrolimulids, meanwhile, may have developed in response to unidirectional hydrodynamic environments that the group encountered as it radiated in lacustrine environments. It is worth considering that macroevolutionary ratchets in even closely related groups may occur through distinct mechanisms.

Ultimately, one of the more interesting outcomes of the study is the support for the quasi-independence of the signal imparted by history and ecology in evolution. History (as represented by phylogeny) and ecology are both significant sources of variation among heterochronic weights but do not interact (Table 4), indicating that although they both exert influence on the distribution of heterochronic weights, they do so with conflicting signals. This conflict is due to the impact of the quasi-independent genealogical and ecological biological hierarchies (Congreve et al. 2018), whereby historical contingency limits the morphological framework for subsequent adaptation to ecological pressures (Gould and Lewontin 1979; Eldredge and Salthe 1984; Anderson and Allmon 2018). Logically, and as hinted at by the data discussed here, this tension between competing hierarchies can also extend to developmental frameworks as the mediating factors by which morphologic phenotypes are expressed.

\section{Conclusions}

Applying this new method for quantifying heterochrony, expressed as a heterochronic weighting, within a phylogenetic context reveals concerted independent heterochronic trends in xiphosurans. These trends correlate with, and may be driven by, shifts in environmental occupation from marine to nonmarine habitats, resulting in a macroevolutionary ratchet whereby environmental selective factors result in the preferential retention of phenotypes derived from heterochronic processes, which in turn reinforces directional heterochronic trends and the proliferation of peramorphic or paedomorphic characteristics. Critically, the distribution of heterochronic weightings among species shows evidence of being influenced by both historical, phylogenetic processes and external ecological pressures. This is most clearly demonstrated by the manner in which the independent occupation of nonmarine environments is accompanied by significant heterochronic trends in both Bellinurina and Austrolimulidae, but manifesting as a paedomorphic trend among bellinurines and a peramorphic trend within austrolimulids. Therefore, while the environment can exert a strong pressure on both phenotype (as expected by the fundamental evolutionary process of natural selection) and the underlying developmental processes that govern phenotype, it can only do so utilizing the available morphological and developmental frameworks. The availability and composition of these frameworks is mediated by contingent, historical factors (as expressed by phylogeny) that limit both the potential for adaptation to certain environmental conditions and the structural or developmental outcome of concerted selective pressure. A well-known example of the former is the fact that vertebrates returning to fully aquatic environments are constrained to breathing air, while a structural example of the latter are the hook-like projections of the beak's tomia in mergansers that are used to aid in gripping their fish prey. The serrations perform a function similar to that of the narrow, curved teeth of gars, which also prey upon small fish. Teeth, however, were lost in the avian stem-lineage; lacking the developmental framework to express teeth, mergansers instead developed modifications to the serrated tomia prevalent in ducks and geese. Xiphosurans demonstrate that such contingent processes can also affect the mechanisms by which developmental shifts occur.

Heterochronic weighting has the proven potential to be an effective method to quantify heterochronic trends within a phylogenetic framework. Comparing the observed heterochronic weightings of clades to randomized distributions permits the discrimination of concerted heterochronic trends from what would be expected under random (nondirectional) character change. The method is readily applicable to any group of organisms that have welldefined morphological characteristics, ontogenetic information, and resolved internal relationships; indeed, in order to test the generality 
of the observations made for xiphosurans, it is imperative that additional studies be performed in disparate clades. Future work should also aim to apply node-based heterochronic weighting in appropriate groups and seek to apply both tip- and node-based calculations to the same data to further explore the behavior and comparability of both. The combination of this heterochronic metric with ecological affinity data affords easy study of the correlation between developmental changes and environmental shifts as a branch of phylogenetic paleoecology and has the potential to open new avenues into studying the relationship between evolutionary developmental processes and external environmental causal factors.

\section{Acknowledgments}

I thank E. Lazo-Wasem (Yale Peabody Museum) for providing photographs of Limulus instars and A. Downey (West Virginia University) for coding assistance that aided in collating randomization results. The concepts and perspectives presented in this paper have been refined over the years through in-depth discussion with my colleagues B. Anderson (West Virginia University), C. Congreve (North Carolina State University), A. Falk (Centre College), A. Manafzadeh (Brown University), and J. Miyamae (Yale University). I am especially grateful to A. Whitaker (University of Kansas) who provided graphical design services to aid in the presentation of this research at the Geological Society of America annual conference and possesses invaluable skills in helping to reassemble 3D printed turtle skulls. I thank D. Bapst (Texas A\&M University) and an anonymous referee for their detailed and thoughtful reviews that greatly improved the article and prompted me to clarify aspects of the method, as well as encouraging me to devote further page space to explanations of macroevolutionary phenomena.

\section{Literature Cited}

Allmon, W. D. 1994. Patterns and processes of heterochrony in Lower Tertiary turritelline gastropods, U.S. Gulf and Atlantic Coastal plains. Journal of Paleontology 68:80-95.

Anderson, B. M., and W. D. Allmon. 2018. When domes are spandrels: on septation in turritellids (Cerithioidea) and other gastropods. Paleobiology 44:444-459.
Anderson, L. I. 1997. The xiphosuran Liomesaspis from the Montceau-les-Mines Konservat-Lagerstätte, Massif Central, France. Neues Jahrbuch für Geologie und PaläontologieAbhandlungen 204:415-436.

Bardin, J., I. Rouget, and F. Cecca. 2017. Ontogenetic data analyzed as such in phylogenies. Systematic Biology 66:23-37.

Benton M. J. 2010. The origins of modern biodiversity on land. Philosophical Transactions of the Royal Society of London B 365:3667-3679.

Benton, M. J., and R. Hitchin. 1997. Congruence between phylogenetic and stratigraphic data on the history of life. Proceedings of the Royal Society of London B 264:885-890.

Benton, M. J., and G. W. Storrs. 1994. Testing the quality of the fossil record: paleontological knowledge is improving. Geology 22:111-114

Bhullar, B.-A. S. 2012. A phylogenetic approach to ontogeny and heterochrony in the fossil record: cranial evolution and development in anguimorphan lizards (Reptilia: Squamata). Journal of Experimental Zoology B 318B:521-530.

Bhullar, B.-A. S., J. Marugán-Lobón, F. Racimo, G. S. Bever, T. B. Rowe, M. A. Norrell, and A. Abzhanov. 2012. Birds have paedomorphic dinosaur skulls. Nature 487:223-226.

Błażejowski, B., G. Niedźwiedzki, K. Boukhalfa, and M. Soussi. 2017. Limulitella tejraensis, a new species of limulid (Chelicerata, Xiphosura) from the Middle Triassic of southern Tunisia (Saharan Platform). Journal of Paleontology 91:960-967.

Botton, M. L., R. A. Tankersley, and R. E. Loveland. 2010. Developmental ecology of the American horseshoe crab Limulus polyphemus. Current Zoology 56:550-562.

Bremer, K. 1994. Branch support and tree stability. Cladistics 10:295-304.

Breton, G. 1997. Patterns and processes of heterochrony in Mesozoic goniasterid sea-stars. Lethaia 30:135-144.

Carrano, M. T. 2000. Homoplasy and the evolution of dinosaur locomotion. Paleobiology 26:489-512.

Carrano, M. T. 2006. Body-size evolution in the Dinosauria. Pp. 225-268 in M. T. Carrano, T. J. Gaudin, R. W. Blob, and J. R. Wible, eds. Amniote paleobiology. University of Chicago Press, Chicago.

Colangelo, P., D. Ventura, P. Piras, J. P. G. Bonaiuti, and G. Ardizzone. 2019. Are developmental shifts the main driver of phenotypic evolution in Diplodus spp. (Perciformes: Sparidae)? BMC Evolutionary Biology 19:106.

Congreve, C. R., and J. C. Lamsdell. 2016. Implied weighting and its utility in palaeontological datasets: a study using modelled phylogenetic matrices. Palaeontology 59:447-462.

Congreve, C. R., A. R. Falk, and J. C. Lamsdell. 2018. Biological hierarchies and the nature of extinction. Biological Reviews 93:811-826

Crônier, C., S. Renaud, R. Feist, and J.-C. Auffray. 1998. Ontogeny of Trimerocephalus lelievrei (Trilobita, Phacopida), a representative of the Late Devonian phacopine paedomorphocline: a morphometric approach. Paleobiology 24:359-370.

Darwin, C. R. 1859. On the origin of species by means of natural selection; or the preservation of favoured races in the struggle for life. Bantam Books, New York.

Davis, K. E., S. De Grave, C. Delmer, and M. A. Wills. 2018. Freshwater transitions and symbioses shaped the evolution and extant diversity of caridean shrimps. Communications Biology $1: 16$.

Ehlinger, G. S., and R. A. Tankersley. 2007. Reproductive ecology of the American horseshoe crab Limulus polyphemus in the Indian River Lagoon: an overview. Florida Scientist 70:449-463.

Eldredge, N. I., and S. N. Salthe. 1984. Hierarchy and evolution. Oxford Surveys in Evolutionary Biology 1:184-208.

Erwin, D. H. 2015a. Novelty and innovation in the history of life. Current Biology 25:R930-R940. 
Erwin, D. H. 2015b. Was the Ediacaran-Cambrian radiation a unique evolutionary event? Paleobiology 41:1-15.

Erwin, D. H. 2017. The topology of evolutionary novelty and innovation in macroevolution. Philosophical Transactions of the Royal Society of London B 372:20160422.

Erwin, D. H., and J. W. Valentine. 2013. The Cambrian explosion: the construction of animal biodiversity. Roberts and Company, Greenwood, Colo.

Farley, R. D. 2010. Book gill development in embryos and first and second instars of the horseshoe crab Limulus polyphemus L. (Chelicerata, Xiphosura). Arthropod Structure \& Development 39:369-381.

Farris, J. S., V. A. Albert, M. Källersjö, D. Lipscomb, and A. G. Kluge. 1996. Parsimony jackknifing outperforms neighbor-joining. Cladistics 12:99-124

Felsenstein, J. 1985. Confidence limits on phylogenies: an approach using the bootstrap. Evolution 39:783-791.

Fernandez-Lopez, S. R., and G. Pavia. 2015. Mollistephaninae and Frebolditinae, new subfamilies of Middle Jurassic stephanoceratid Ammonoidea. Paläontologische Zeitschrift 89:707-727.

Gauthier, J., A. G. Kluge, and T. Rowe. 1988. Amniote phylogeny and the importance of fossils. Cladistics 4:105-209.

Gerber, S. 2011. Comparing the differential filling of morphospace and allometric space through time: the morphological and developmental dynamics of Early Jurassic ammonoids. Paleobiology 37:369-382.

Goloboff, P. A., J. A. Farris, and K. C. Nixon. 2008. TNT, a free program for phylogenetic analysis. Cladistics 24:774-786.

Gould, S. J. 1982. The meaning of punctuated equilibrium and its role in validating a hierarchical approach to macroevolution. Pp. 83-104 in R. Milkman, ed. Perspectives on evolution. Sinauer, Sunderland, Mass.

Gould, S. J. 1988. The uses of heterochrony. Pp. 1-13 in M. L, McKinney, ed. Heterochrony in evolution: a multidisciplinary approach. Plenum, New York.

Gould, S. J., and R. C. Lewontin. 1979. The spandrels of San Marco and the Panglossian paradigm: a critique of the adaptationist programme. Proceedings of the Royal Society of London B 205:581-598.

Hammer, Ø., D. A. T. Harper, and P. D. Ryan. 2001. PAST: Paleontological Statistics software package for education and data analysis. Palaeontologia Electronica 4(1).

Harzsch, S., K. Vilpoux, D. C. Blackburn, D. Platchetzki, N. L. Brown, R. Melzer, K. E. Kempler, and B. A. Battelle. 2006. Evolution of arthropod visual systems: development of the eyes and central visual pathways in the horseshoe crab Limulus polyphemus Linnaeus, 1758 (Chelicerata, Xiphosura). Developmental Dynamics 235:2641-2655.

Haug, C., and M. A. I. N. Rötzer. 2018a. The ontogeny of Limulus polyphemus (Xiphosura s. str., Euchelicerata) revised: looking "under the skin." Development Genes and Evolution 228:49-61.

Haug, C., and M. A. I. N. Rötzer. 2018b. The ontogeny of the 300 million year old xiphosuran Euproops danae (Euchelicerata) and implications for resolving the Euproops species complex. Development Genes and Evolution 228:63-74.

Haug, C., P. Van Roy, A. Leipner, P. Funch, D. M. Rudkin, L. Schöllmann, and J. T. Haug. 2012. A holomorph approach to xiphosuran evolution - a case study on the ontogeny of Euproops. Development Genes and Evolution 222:253-268.

Holder, M. T., J. Sukumaran, and P. O. Lewis. 2008. A justification for reporting the majority-rule consensus tree in Bayesian phylogenetics. Systematic Biology 57:814-821.

Hopkins, M. J. 2014. The environmental structure of trilobite morphological disparity. Paleobiology 40:352-373.

Hopkins, M. J., and S. Gerber. 2017. Morphological disparity. Pp. 1-11 in L. Nuño de la Rosa and G. B. Müller, eds. Evolutionary developmental biology. Springer, Cham, Switzerland.

Hopkins, M. J., and S. Lidgard. 2012. Evolutionary mode routinely varies among morphological traits within fossil species lineages.
Proceedings of the National Academy of Sciences USA 109:2052020525.

Hu, S., Q. Zhang, R. M. Feldmann, M. J. Benton, C. E. Schweitzer, W. Wen, C. Zhou, T. Xie, T. Lü, and S. Hong. 2017. Exceptional appendage and soft-tissue preservation in a Middle Triassic horseshoe crab from SW China. Scientific Reports 7:14112.

Huelsenbeck, J. P., and F. Ronquist. 2001. MRBAYES: Bayesian inference of phylogenetic trees. Bioinformatics 17:754-755.

Hunt, G., M. J. Hopkins, and S. Lidgard. 2015. Simple versus complex models of trait evolution and stasis as a response to environmental change. Proceedings of the National Academy of Sciences USA 112:4885-4890.

Huttenlocker, A. K. 2014. Body size reductions in nonmammalian eutheriodont therapsids (Synapsida) during the end-Permian mass extinction. PLoS ONE 9:e87553.

Jones, D. S. 1988. Sclerochronology and the size versus age problem. Pp. 93-108 in M. L. McKinney, ed. Heterochrony in evolution: a multidisciplinary approach. Plenum, New York.

Kiessling, W., and M. Aberhan. 2007. Environmental determinants of marine benthic biodiversity dynamics through Triassic-Jurassic time. Paleobiology 33:414-434.

Korn, D. 1995. Paedomorphosis of ammonoids as a result of sealevel fluctuations in the Late Devonian Wocklumeria Stufe. Lethaia 28:155-165.

Korn, D., M. J. Hopkins, and S. A. Walton. 2013. Extinction space-a method for the quantification and classification of changes in morphospace across extinction boundaries. Evolution 67:27952810 .

Lamsdell, J. C. 2013. Revised systematics of Palaeozoic "horseshoe crabs" and the myth of monophyletic Xiphosura. Zoological Journal of the Linnean Society 167:1-27.

Lamsdell, J. C. 2016. Horseshoe crab phylogeny and independent colonisations of freshwater: ecological invasion as a driver for morphological innovation. Palaeontology 59:181-194.

Lamsdell, J. C. 2019. A chasmataspidid affinity for the putative xiphosuran Kiaeria Størmer, 1934. Paläontologische Zeitschrift. doi: 10.1007/s12542-019-00493-8.

Lamsdell, J. C. In press. Evolutionary history of the dynamic horseshoe crab. International Wader Studies 21.

Lamsdell, J. C., and S. C. McKenzie. 2015. Tachypleus syriacus (Woodward) - a sexually dimorphic Cretaceous crown limulid reveals underestimated horseshoe crab divergence times. Organisms Diversity \& Evolution 15:681-693.

Lamsdell, J. C., D. E. G. Briggs, H. P. Liu, B. J. Witzke, and R. M. McKay. 2015. A new Ordovician arthropod from the Winneshiek Lagerstätte of Iowa (USA) reveals the ground plan of eurypterids and chasmataspidids. Science of Nature 102:63.

Lamsdell, J. C., C. R. Congreve, M. J. Hopkins, A. Z. Krug, and M. E. Patzkowsky. 2017. Phylogenetic paleoecology: tree-thinking and ecology in deep time. Trends in Ecology and Evolution 32:452-463.

Lamsdell, J. C., J. N. Tashman, G. Pasini, and A. Garassino. 2020. A new limulid (Chelicerata, Xiphosurida) from the Late Cretaceous (Cenomanian-Turonian) of Gara Sbaa, southeast Morocco. Cretaceous Research 106:104230.

Lerner, A. J., S. G. Lucas, and C. F. Mansky. 2016. The earliest paleolimulid and its attributed ichnofossils from the Lower Mississippian (Tournasian) Horton Bluff Formation of Blue Beach, Nova Scotia, Canada. Neues Jahrbuch für Geologie und Paläontologie—Abhandlungen 280:193-214.

Lerner, A. J., S. G. Lucas, and M. Lockley. 2017. First fossil horseshoe crab (Xiphosurida) from the Triassic of North America. Neues Jahrbuch für Geologie und Paläontologie-Abhandlungen 286:289-302.

Lewis, P. O. 2001. A likelihood approach to estimating phylogeny from discrete morphological character data. Systematic Biology 50:913-925. 
Losos, J. B. 2010. Adaptive radiation, ecological opportunity, and evolutionary determinism. American Naturalist 175:623-639.

Maddison, W. P., and D. R. Maddison. 2018. Mesquite: a modular system for evolutionary analysis, version 3.51. http://www.mesquiteproject.org, accessed 10 August 2019.

Martynov, A., K. Lundin, B. Picton, K. Fletcher, K. Malmberg, and T. Korshunova. 2020. Multiple paedomorphic lineages of softsubstrate burrowing invertebrates: parallels in the origin of Xenocratena and Xenoturbella. PLoS ONE 15:e0227173.

McKinney, M. L. 1986. Ecological causation of heterochrony: a test and implications for evolutionary theory. Paleobiology 12:282289.

McKinney, M. L. 1988. Classifying heterochrony. Allometry, size and time. Pp. 17-34 in M. L. McKinney, ed. Heterochrony in evolution: a multidisciplinary approach. Plenum, New York.

McKinney, M. L. 1999. Heterochrony: beyond words. Paleobiology 25:149-153.

McNamara, K. J. 1982. Heterochrony and phylogenetic trends. Paleobiology 8:130-142.

McNamara, K. J. 1986. The role of heterochrony in the evolution of Cambrian trilobites. Biological Reviews 61:121-156.

McNamara, K. J. 1988. Patterns of heterochrony in the fossil record. Trends in Ecology and Evolution 3:176-180.

McNamara, K. J. 2012. Heterochrony: the evolution of development. Evolution: Education and Outreach 5:203-218.

McNamara, K. J., and M. L. McKinney. 2005. Heterochrony, disparity, and macroevolution. Paleobiology 31:17-26.

Miller, A. I., and S. R. Connolly. 2001. Substrate affinities of higher taxa and the Ordovician radiation. Paleobiology 27:768-778.

Naugolnykh, S. V. 2017. Lower Kungurian shallow-water lagoon biota of Middle Cis-Urals, Russia: towards paleoecological reconstruction. Global Geology 20:1-13.

Norell, M. A. 1993. Tree-based approaches to understanding history: comments on ranks, rules, and the quality of the fossil record. American Journal of Science 293A:407-417.

Norell, M. A., and M. J. Novacek. 1992a. Congruence between superpositional and phylogenetic patterns: comparing cladistic patterns with fossil records. Cladistics 8:319-337.

Norell, M. A., and M. J. Novacek. 1992b. The fossil record and evolution: comparing cladistic and paleontologic evidence for vertebrate history. Science 255:1690-1693.

Oksanen, J., F. G. Blanchet, M. Friendly, R. Kindt, P. Legendre, D. McGlinn, P. R. Michin, R. B. O'Hara, G. L. Simpson, P. Solymos, M. H. H. Stevens, E. Szoecs, and H. Wagner. 2019. Package 'vegan'. https://cran.r-project.org/web/packages/ vegan/index.html, accessed 12 February 2020.

O'Leary, M. A., and S. G. Kaufman. 2012. MorphoBank 3.0: web application for morphological phylogenetics and taxonomy. http://www.morphobank.org, accessed 2 June 2019.

O'Reilly, J. E., M. N. Puttick, L. Parry, A. R. Tanner, J. E. Tarver, J. Fleming, D. Pisani, and P. C. J. Donoghue. 2016. Bayesian methods outperform parsimony but at the expense of precision in the estimation of phylogeny from discrete morphological data. Biology Letters 12:20160081.

Poty, E. 2010. Morphological limits to diversification of the rugose and tabulate corals. Palaeoworld 19:389-400.

Poulin, R. 2005. Evolutionary trends in body size of parasitic flatworms. Biological Journal of the Linnean Society 85:181-189.

Prado, J. L., and M. T. Alberdi. 2008. Cladistic analysis among trilophodont gompotheres (Mammalia, Proboscidea) with special attention to the South American genera. Palaeontology 51:903915.

Puttick, M. N., J. E. O’Reilly, A. R. Tanner, J. F. Fleming, J. Clark, L. Holloway, J. Lozano-Fernandez, L. A. Parry, J. E. Tarver, D. Pisani, and P. C. J. Donoghue. 2017. Uncertain-tree: discriminating among competing approaches to the phylogenetic analysis of phenotype data. Proceedings of the Royal Society of London B 284:20162290.

Puttick, M. N., J. E. O'Reilly, D. Pisani, and P. C. J. Donoghue. 2019. Probabilistic methods outperform parsimony in the phylogenetic analysis of data simulated without a probabilistic method. Palaeontology 62:1-17.

Racheboeuf, P. R., J. Vannier, and L. I. Anderson. 2002. A new three-dimensionally preserved xiphosuran chelicerate from the Montceau-les-Mines Lagerstätte (Carboniferous, France). Palaeontology 45:125-147.

R Core Team. 2018. R: a language and environment for statistical computing. R Foundation for Statistical Computing, Vienna, Austria. http://www.r-project.org.

Sansom, R. S., P. G. Choate, J. N. Keating, and E. Randle. 2018. Parsimony, not Bayesian analysis, recovers more stratigraphically congruent phylogenetic trees. Biology Letters 14:20180263.

Saupe, E. E., J. R. Hendricks, R. W. Portell, H. J. Dowsett, A. Haywood, S. J. Hunter, and B. S. Lieberman. 2014. Macroevolutionary consequences of profound climate change on niche evolution in marine molluscs over the past three million years. Proceedings of the Royal Society of London B 281:20141995.

Saupe, E. E., H. Qiao, J. R. Hendricks, R. W. Portell, S. J. Hunter, J. Soberón, and B. S. Lieberman. 2015. Niche breadth and geographic range size as determinants of species survival on geological time scales. Global Ecology and Biogeography 24:1159-1169.

Scholl, G. 1977. Beiträge zur Embryonalentwicklung von Limulus polyphemus L. (Chelicerata, Xiphosura). Zoomorphologie 86:99154.

Schultka, S. 2000. Zur palökologie der Euproopiden im Nordwestdeutschen Oberkarbon. Mitteilungen aus dem Museum für Naturkunde in Berlin, Geowissenschaftliche Reihe 3:87-98.

Sekiguchi, K. 1988. Embryonic development. Pp. 145-181 in K. Sekiguchi, ed. Biology of horseshoe crabs. Science House, Tokyo.

Sekiguchi, K., Y. Yamamichi, and J. D. Costlow. 1982. Horseshoe crab developmental studies I. Normal embryonic development of Limulus polyphemus compared with Tachypleus tridentatus. Pp. 53-73 in J. Bonaventura, C. Bonaventura, and S. Tesh, eds. Physiology and biology of horseshoe crabs: studies on normal and environmentally stressed animals. Liss, New York.

Sekiguchi, K., H. Seshimo, and H. Sugita. 1988a. Post-embryonic development. Pp. 181-195 in K. Sekiguchi, ed. Biology of horseshoe crabs. Science House, Tokyo.

Sekiguchi, K., H. Seshimo, and H. Sugita. 1988b. Post-embryonic development of the horseshoe crab. Biological Bulletin 174:337345 .

Selden, P. A., and D. J. Siveter. 1987. The origin of the limuloids. Lethaia 20:383-392.

Selden, P. A., J. C. Lamsdell, and Q. Liu. 2015. An unusual xiphosuran linking horseshoe crabs and eurypterids, from the Lower Devonian (Lochkovian) of Yunnan, China. Zoologica Scripta 44:645-652.

Shpinev, E. S., and D. V. Vasilenko. 2018. First fossil xiphosuran (Chelicerata, Xiphosura) egg clutch from the Carboniferous of Khakassia. Paleontological Journal 52:400-404.

Shuster, C. N. Jr. 1982. A pictorial review of the natural history and ecology of the horseshoe crab, Limulus polyphemus, with reference to other Limulidae. Pp. 1-52 in J. Bonaventura, C. Bonaventura, and S. Tesh, eds. Physiology and biology of horseshoe crabs: studies on normal and environmentally stressed animals. Liss, New York

Shuster, C. N. Jr., and K. Sekiguchi. 2003. Growing up takes about ten years and eighteen stages. Pp. 103-132 in C. N. Shuster Jr., R. B. Barlow, and H. J. Brockmann, eds. The American horseshoe crab. Harvard University Press, Cambridge, Mass.

Simms, M. J. 1988. Patterns of evolution among Lower Jurassic crinoids. Historical Biology 1:17-44. 
Simpson, C., and P. G. Harnik. 2009. Assessing the role of abundance in marine bivalve extinction over the post-Paleozoic. Paleobiology 35:631-647.

Spearman, C. 1904. A proof and measurement of association between two things. American Journal of Psychology 15:72101.

Stroud, J. T., and J. B. Losos. 2016. Ecological opportunity and adaptive radiation. Annual Review of Ecology, Evolution, and Systematics 47:507-532.

Tasch, P. 1961. Paleolimnology: Part 2-Harvey and Sedgwick counties, Kansas: stratigraphy and biota. Journal of Paleontology 35:836-865.

Tashman, J. N., R. M. Feldmann, and C. E. Schweitzer. 2019. Morphological variation in the Pennsylvanian horseshoe crab Euproops danae (Meek \& Worthen, 1865) (Xiphosurida, Euproopidae) from the lower Mercer Shale, Windber, Pennsylvania, USA. Journal of Crustacean Biology 39:396-406.

Toljagić, O., and R. J. Butler. 2013. Triassic-Jurassic mass extinction as trigger for the Mesozoic radiation of crocodylomorphs. Biology Letters 9:20130095.

Tucker, C. M., M. W. Cadotte, S. B. Carvalho, J. T. Davies, S. Ferrier, S. A. Fritz, R. Grenyer, M. R. Helmus, L. S. Jin, A. Ø. Mooers, S. Pavoine, O. Purschke, D. W. Redding, D. F. Rosauer, M. Winter, and F. Mazel. 2017. A guide to phylogenetic metrics for conservation, community ecology and macroecology. Biological Reviews 92:698-715
Van Valkenburgh, B. 1991. Iterative evolution of hypercarnivory in canids (Mammalia, Carnivora) - evolutionary interactions among sympatric predators. Paleobiology 17:340-362.

Van Valkenburgh, B. 1999. Major patterns in the history of carnivorous mammals. Annual Review of Earth and Planetary Sciences 27:463-493.

Van Valkenburgh, B., X. Wang, and J. Damuth. 2004. Cope's rule, hypercarnivory, and extinction in North American canids. Science 306:101-104.

Vrba, E. S., and N. Eldredge. 1984. Individuals, hierarchies and processes: towards a more complete evolutionary theory. Paleobiology 10:146-171.

Wagner, P. J., and C. A. Sidor. 2000. Age rank/clade rank metricssampling, taxonomy, and the meaning of "stratigraphic consistency." Systematic Biology 49:463-479.

Watson, D. M. S. 1909. Limulus woodwardi, sp. nov., from the Lower Oolite of England. Geological Magazine 6:14-16.

Wright, A. M., and D. M. Hillis. 2014. Bayesian analysis using a simple likelihood model outperforms parsimony for estimation of phylogeny from discrete morphological data. PLoS ONE 9: e109210.

Yoder, J. B., E. Clancey, S. Des Roches, J. M. Eastman, L. Gentry, W. Godsoe, T. J. Hagey, D. Jochimsen, B. P. Oswald, J. Robertson, B. A. J. Sarver, J. J. Schenks, S. F. Spear, and L. J. Harmon. 2010. Ecological opportunity and the origin of adaptive radiations. Journal of Evolutionary Biology 23:1581-1596. 